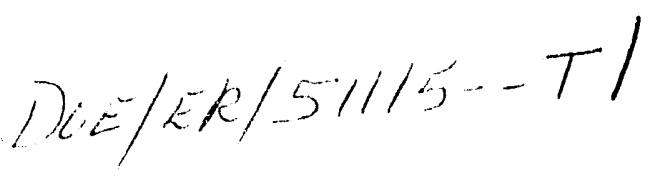

\section{EQUILIBRIUM SYSTEM ANALYSIS IN A TOKAMAK IGNITION EXPERIMENT}

Final Report to the

Office of Fusion Energy

Office of Energy Research

U.S. Department of Energy

Technical Monitor: Dr. C.W. Bolton Division of Confinement Systems ER-55, OFE, OER, USDOE 19901 Germantown Road Germantown, MD 20874

Contract Number: $\quad$ DE-FG05-88ER51115

Principal Investigators: Dr. R. Carrera Professor W.F. Weldon Professor H.H. Woodson Center for Fusion Engineering The University of Texas Austin, TX 78712

OCTOBER 1989 
TABLE OF CONTENTS

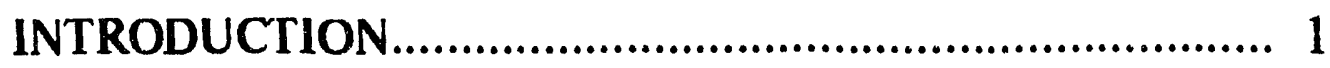

IGNITEX EXPERIMENT ........................................... 3

PROPOSAL OBJECTIVES AND WORK PLAN ..................... 7

STRUCTURAL EDDY CURRENT EFFECTS ON

PLASMA EQUILIBRIUM.................................................. 10

ANALYSIS OF THE POLOIDAL FIELD SYSTEM LEADS.. 16

CONCLUSIONS......................................................... 21

APPENDIX (IGNITEX Publications and Presentations

Partially Funded by this Grant)................................. 28 


\section{INTRODUCTION}

The objective of the IGNITEX project is to produce and control ignited plasmas for scientific study in the simplest and least expensive way possible. The original concept was proposed by Professors M. N. Rosenbluth, W. F. Weldon, and H. H. Woodson [1] at The University of Texas at Austin on the basis of B. Coppi's idea of a compact ignition experiment and recent technology advances in pulsed power high current systems

Some of the unique fentures of the IGNITEX project are:

- The original concept was proposed by both physics and engineering researchers along the following line of thought. Question: Is there any theoretically simple, compact and reliable way of achiaving fusion ignition according to the results of the fusion research program for the last decades? Answer: Yes. An experiment to be carried out in an ohmically heated compact tokamak device with $20 \mathrm{~T}$ field on plasma axis. Question: Is there any practical way to carry out that experiment at low cost in the near term? Answer: Yes. Using a single-turn coil magnet system with homopolar power supplies.

- The initial funding for the project was provided by electric utilities (through the Texas Atomic Energy Research Foundation - TAERF) that is made of the ten investor-owned electric utilities that operate in the state of Texas).

- There has been a significant amount of volunteer (non-paid) work involved in the development of the plasma physics, electromechanics, and nuclear engineering aspects of the concept to date.

The IGNITEX Project was started three years ago with a grant to study the basic fusion physics and electromechanics aspects of the experiment (TAERF, $\$ 350 \mathrm{~K}$ for 2 years). Last year three grants were awarded to the project for: study of the basic fusion engineering aspects (Texas Advanced Technology Program - TATP, $\$ 350 \mathrm{~K}$ for 2 years), 
design, fabrication, and testing of a magnet prototype (TATP, $\$ 900 \mathrm{~K}$ for 1.75 years), and physics and electromechanics analysis of the equilibrium system (US DOE $\$ 100 \mathrm{~K}$ for 1 year). Over 50 people have been involved in the project from 12 UT-Austin research centers, and outside laboratories. Over 100 reports have been written in the various fusion physics, electromechanics, and fusion engineering aspects of the experiment. Over 60 presentations have been given on IGNITEX, including invited seminars at the major fusion laboratories in the USA and overseas. During this time, a system of numerical codes (over 60 programs from UT and fusion laboratories in the USA and overseas) have been put together for the design and analysis of the various physics and engineering aspects of the experiment. A novel fusion magnet technology development has been undertaken.

Recently, a proposal has been submitted to the US Department of Energy [2] for the preliminary design of the fusion ignition experiment (IGNITEX) and for a generator technology demonstration (\$11 M for 2 years). The proposed IGNITEX Project schedule is indicated in Table 1.

The IGNITEX project emphasizes:

- Simplicity

- Reliability

- Low Cost

- Effective design and analysis interaction between the various work areas relevant to the realization of the experiment (see Table 2).

- Technology Demonstration is parallel to the Design and Analysis. The proposed elements of the Ignition Technology Demonstration Program are: TF magnet (now underway [3]), HPG generator (proposed [2]), and PF magnet. 


\section{IGNITEX EXPERIMENT}

The IGNITEX concept is based on the idea of a single-turn-coil tokamak. This device will permit the production of higher than usual magnetic fields and then:

- Ohmic ignition (L-mode of operation)

- Operation far from marginal stability

- Control of thermal instability at ignition

A single-turn-coil tokamak is a very low impedance system that requires special power supplies that can handle very high currents at very low voltages. Homopolar generators are well suited to supply power to a single-turn-coil tokamak. The concept of a single-turn-coil tokamak provides a feasible, simple, and low-cost approach to high-field tokamak confinement. The interest on this type of confinement system stems from the fact that it is the fusion system with the most immediate prospects for producing ignited plasmas at low cost.

A cross-section of the IGNITEX single-turn-coil tokamak is given in Figure 1. The experiment at the time of ignition is described in Table 3. The total pulse length envisioned for the experiment is 10 seconds (Figure 2). There is a current ramping of $3 \mathrm{~s}$, a flat top of $5 \mathrm{~s}$, and a shut down phase of $2 \mathrm{~s}$.

Next, we outline some of the characteristics of the IGNITEX experiment. The plasma characteristics are:

- High field

- Compact

- High current

- High ignition margin (L-mode)

- Ohmic heating

- Low beta

- Low flux requirement 
- Good equilibrium

- Good control

- High alpha containment

- Moderate neutron w/all lizad

- Control thermal instability

- Moderate elongation

- No divertor

- No auxiliary heating.

The magnet system characteristics are:

- TF single-turn coil, high filling factor, high strength, low current density, no windings, low voltage, and simplicity.

- PF internal to TF coil: an internal inductor made of ten single-turn coils provides good plasma coupling and permits to use a central compression barthat increases the strength of the TF magnet system.

- The use of a central compression bar, active axial preloading, and radial preloading makes the stresses tolerable.

- Cryogenic precooling allows for the lengthening of the pulse.

The power supply system is made of homopolar generators ( 12 for the TF system and 5 for the PF system) which have the following characteristics:

- High current

- Low voltage

- Energy store in long periods of time

- Large power pulse in short period of time

- Direct current

- Compact

- Reliable

- Iron-core technology

- High-speed composite flywheel

- Low cost 
The characteristics of the nuclear island are:

- Low activation

- Low-level waste disposal

- No tritium recycling

- Low environmental impact

- Be-coated vacuum vessel

- No use of: limiter, plates, or tiles

- First-wall maintenance: plasma gun in a $90^{\circ}$ robotic arm

- Diagnosis system in experimental hall (full access)

- Turbo-pump vacuum system

- Limiterless operation

- Generator ringing

- High density breakdown by resonant cavity modes

- Hands-on, out-vessel maintenance

- Low cost experiment

A conceptual machine-level floor plan for the IGNITEX experiment is given in Figure 3.

The scientific and technological bases for the IGNITEX experiment are well established. From the scientific point of view the IGNITEX concept relies on three basic premises.

- Plasma physics experiments in ohmically-heated high-field tokamaks have provided record confinement product and plasma purity. In addition, the ohmic regime of operation in tokamaks is the fusion research's best established mode of operation.

- High plasma current in tokamak operation should improve plasma energybalance (by increasing alpha heating and ohmic heating and decreasing plasmaenergy loses) and relaxes operation conditions (by increasing the Troyon andMurakami limits).

- High values of $\mathrm{B}^{2} \mathrm{ak}^{2}$ are required for ohmic ignition. The ignition accessibilityconditions: $\mathrm{POH}_{\mathrm{OH}}>\mathrm{P}_{\mathrm{E}}, \mathrm{T}\left(\mathrm{P}_{\mathrm{OH}}-\mathrm{P}_{\mathrm{E}}\right)>\mathrm{T}\left(\mathrm{P}_{\mathrm{FUS}}-\mathrm{P}_{\mathrm{RAD}}\right)$, 
and $n\left(P_{O H}-P_{R A D}\right)>n\left(P_{F U S}-P_{E}\right)$ are satisfied for high values of $B^{2} a^{2}$, which in IGNITEX is greater than 500 .

From the technology point of view, the IGNITEX concept is based on the following:

- Single-turn-coil magnet systems provide a simple and low cost means to produce high magnetic fields and induce high plasma currents.

- Homopolar generators are low cost and well suited power supplies for single-turn-coil magnet systems.

- A single-turn-coil tokamak provides an environmentally-clean ignition experiment. follows:

The objectives of the IGNITEX experiment can be outlined as

- prove the scientific feasibility of controlled thermonuclear fusion

- study of a new regime of physics: ignited plasmas

- obtain scientific knowledge for the design of future fusion systems

- learn how to produce and control fusion

The IGNITEX experiment is significantly different from other previously proposed compact ignition experiments in the:

- Ample physics margins

- Magnet and power supply technologies

- Benign environmental characteristics

- Design simplicity

- Low cost

The cost for the basic construction of the IGNITEX experiment is estimated at $\$ 130 \mathrm{M}$. A cost breakdown is presented in Table 4. 
Some of the advantages of the IGNITEX approach for a fusion ignition experiment are:

- Ample ignition margin

- Ignition is predicted without auxiliary heating

- Ignition is predicted without divertor (L-mode)

- Ignition can be reached far from stability limits

- High alpha particle confinement

- The ignited phase can be maintained without exceeding disruptive limits

- Good plasma equilibrium

- Good plasma control

- Design simplicity

- Moderate magnet current density

- High magnet-to-plasma coupling

- Simple magnet systems: no turn-to-turn insulation, no windings, and no turn-to-turn transitions.

- Low voltages operation

- Low grid power

- No current rectification

- Low-activation experiment

- Low-level waste disposal

- Minimum environmental effects

- Relatively low cost

\section{PROPOSAL OBJECTIVES AND WORK PLAN}

The objective of this proposal was to analyze some important aspects of the physics and engineering of the equilibrium system for compact tokamak ignition experiments. In the physics area an analysis of plasma equilibrium accounting for eddy currents in the structure surrounding the plasma column has been carried out. The effects on alpha particle containment of toroidal field ripple have been analyzed. In the engineering area, the fields around internal poloidal field coil leads have been evaluated so that lead geometries that minimize field perturbations can be proposed. 
The magnetic forces on the poloidal field coil leads have been calculated to verify that they can be supported with an appropriate design. The plasma physics analysis provides information needed for the engineering design of a compact ignition experiment. Specifically, it is important to define the field perturbation thresholds imposed by the present ignition physics understanding on the design of the device in order to do an evaluation of technology issues.

In the physics and engineering calculations carried out in this proposal, an internal (to the toroidal field, TF, coil) poloidal field (PF) system is considered. In a high-current elongated compact tokamak, an internal PF system has a number of advantages over other design options. Because the PF coils are close to the plasma column, coupling is rather strong, and then plasma shaping and control are facilitated. In fact, an equilibrium silution for the plasma configuration may not be possible in an external system [4]. Thus, high-current equilibrium configurations are easily attainable [5]. In addition, an internal inductor will reduce the requirements on the $\mathrm{PF}$ power supplies, making them simpler and less expensive than in the case of an external PF system.

The magnet system design is simplified because critical elements of more conventional designs (for example the ohmic transformer and equilibrium coils for the induction of $X$ points) are either not present or subject to lower demands. Because of the proximity of the PF coils to the plasma, 2-X point equilibrium configurations can be easily obtained [5]. Furthermore, locating the PF system inside the TF bore permits use of the torus hole space--typically occupied by the ohmic transformer--to place a high-strength central post, a configuration that will increase the loadcarrying capability of the TF magnet.

Preliminary calculations of plasma equilibrium assuming fixed boundary conditions [6] in the type of system considered here were presented in Ref. 1. More elaborated equilibrium calculations allowing for free boundary conditions [7] and variable PF coil currents were given in Ref. 5. Here we present a study of plasma equilibria accounting for 
structural eddy currents [8]. This study is an essential first step to a subsequent study of alpha particle transport in ignited plasmas. We also present a study of alpha particle transport in nonaxisymmetric tokamak equilibria [9]. This analysis is relevant for the design of an ignition experiment because it determines the level of alpha containment (and then the level of plasma self-heating at ignition) and the tolerable ripple amplitudes in order to reach ignition. In a sense, the detailed study of asymmetries in tokamak confinement becomes important when an ignition tokamak is considered.

The time evolution of the plasma and electromagnetic fields on the resistive time scale have been studied with a finite element code that solves the Grad-Shafranov equation with explicit dependence on eddy currents [8]. The alpha transport in nonaxisymmetric equilibria is studied by following the energetic fusion alpha particles around the torus with binary Coulomb collisions being simulated by Monte Carlo techniques [9]. The alpha transport analysis is needed to determine the level of alpha heating during the ignited phase of the experiment. In addition, it may be important in the design of the first wall because of possible local hot spots of intense alpha particle deposition. The equilibrium analysis permit us to define the amplitude of the field perturbations and therefore the level of alpha losses.

Time-dependent calculations of the thermomechanical stresses and heating of the coils in an internal PF system were presented in Ref. 10. The analysis was carried out with a transient quasi-three-dimensional finite element code that accounts for electromagnetic, thermal, and mechanical phenomena. The code solves the nonlinearly coupled magnetic and heat diffusion equations and calculates the resulting stress, temperature, field, and current distributions as functions of time. In parts of the structure, such as the region in which the leads of the PF coils penetrate into the TF system, a three-dimensional finite element treatment is required and is employed in the proposed work.

In compact ignition experiments of the type considered here, each of the PF terminals can be a pair of parallel plate busbars in which the current 
flows in opposite directions so that they significantly self-cancel the magnetic fields that could locally perturb the field inside the TF bore. The disturbance can be minimized by arranging the terminals in two opposite TF splits so that flat terminals are possible. The field perturbation resulting from the current in the PF leads and the TF coil gap is evaluated during the discharge. The thermomechanical stresses in the PF leads are calculated.

In summary, the following aspects of a tokamak ignition experiment are addressed in this work:

- Structural-eddy-current perturbation of equilibrium configurations

- Alpha-particle contain in nonaxisymmetric conditions

- Analysis of field perturbations induced by PF coil leads

- Thermomechanical stresses in internal poloidal field system leads

The analysis presented here provides a first step in the detailed assessment of the effect of nonaxisymmetries in the structure surrounding a tokamak ignited plasma. This evaluation and the assessment of the feasibility of internal poloidal field systems in ignition machines are important aspects of the design of ignition experiments based on the compact tokamak approach.

\section{STRUCTURAL EDDY CURRENT EFFECTS ON PLASMA EQUILIBRIUM}

The IGNITEX device is a compact, high field tokamak in which the plasma should achieve ignition conditions with ample physics margin by the use of high plasma current alone. One of the major features of the device is the proximity of the PF coils to the plasma and the massive structural conducting material surrounding the plasma chamber. Advantages of such design are numerous from engineering point of view [10]. Since the plasma, the PF coils, and the massive structure are strongly coupled, that makes analysis of plasma equilibrium and eddy current effects complex. 
The plasma equilibrium study constitutes one of the major issues in the design and simulation of the IGNTTEX experiment.

A poloidal cross section of the device is shown in Figure 4. The conducting structural material surrounding the plasma is divided into four layers, vacuum vessel (first wall), PF coils, inner toroidal magnet region, and outer toroidal magnet region. The vacuum vessel and the PF coils are as usual: basically axisymmetric. The inner magnet region is a part of the toroidal field coil where a thin resistive layer $0.076 \mathrm{~cm}$ thick, and extending $1 \mathrm{j} \mathrm{cm}$ from the plasma bore, is installed approximately every $5.8 \mathrm{~cm}$ along the magnetic axis in order to induce the required plasma current [10]. This region is, essentially, non-axisymmetric and is considered as a diffusion region. The outer magnet region is divided into twelve sectors.

The 2-D finite element code PROTEUS [8] is used here to study the plasma current induction and MHD equilibrium evolution with the effects of structural eddy currents included. Some modifications have been introduced in the code in order to properly handle compact tokamak systems with massive conducting structures. These modifications are described below. The results of current induction calculation and the equilibrium configurations throughout the discharge are presented here.

The code PROTEUS is used to study the plasma MHD equilibrium and current induction with structural effects. This 2-D finite element MHD code has been used successfully to evaluate plasma equilibrium in the JET device. Some modifications of the code have been made here in order to simulate the IGNITEX device. These modifications include: (1) use of an interpolation technique to find the position of the magnetic axis with high accuracy (the magnetic axis is fixed on the $\mathrm{z}=0$ plane); (2) consideration of the following convergency criteria 


$$
\begin{aligned}
& \frac{\mid \psi_{a^{-\psi_{a}}}^{n}{ }_{a}^{n+1}}{\left|\begin{array}{l}
n \\
\psi_{a}
\end{array}\right|} \leq \varepsilon_{2}
\end{aligned}
$$

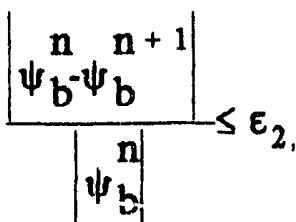

where $\psi_{\mathrm{a}}$ and $\psi_{\mathrm{b}}$ are the fluxes at the magnetic axis and the plasma boundary, respectively and $n$ is the iteration index; (3) use of additional boundary points for the plasma boundary (a total of 30 points used); (4) use of the spline method to get waveforms for the plasma current and the PF coil currents from the current values obtained at separate time points (this smooths the time derivative functions); (5) others, e.g., consideration of limiter configuration and $x$-point configurations, calculation of stresses [11], etc. These modifications do not change the code essentially, but allow for a proper treatment of IGNITEX-type devices.

The main part of the finite element grid used for the IGNITEX device is shown in Figure 5.

In the plasma current induction calculation the plasma is considered as a passive coil filling up the vacuum vessel. The plasma resistivity is taken to be the Spitzer resistivity with neoclassical corrections. The electron temperature is a function of time obtained from an energy balance calculation. The vacuum vessel is considered as a set of circuits connected such that the total current induced in it is zero. The PF coils are active coils driven by given currents. The inner magnet region with slits is a diffusive region with resistivity much higher than that of the vacuum vessel. The outer magnet region is considered as a set of circuits connected in the same way and with the same conductivity as in the vacuum vessel. Two typical cases are given in Figures 6 to 12. In one case, referred to as 
the low resistivity case, the resistivity of the vacuum vessel and the outer magnet region is taken to be the resistivity of copper at room temperature, $1.7 \times 10^{-8} \Omega \mathrm{m}$, while the resistivity of the diffusive region is ten times higher than this value. In the other case, refered to as the high resistivity case, the resistivity of the vacuum vessel and the outer magnet region is taken to be $r=5.1 \times 10^{-6} \Omega \mathrm{m}$ while the diffusive region is considered as vacuum.

The PF coil currents as functions of time are given in Figures 6 to 10. The solid lines correspond to the low resistivity case and the dotted lines to the high resistivity case. The arr'ngement of the PF coils is shown in Figure 4. The PF coil current waveforms provide good MHD plasma equilibrium configurations (see below). The corresponding induced plasma currents are given in Figure 11 and Figure 12, respectively. In both cases, especially in the low resistivity case, the flux swing is sufficient to induce $12 \mathrm{MA}$ of plasma current. The induced plasma current at $t=5$ seconds for the same PF coil current waveforms (the waveforms of the low resistivity case) is given in Figure 13 as a function of the resistivity of the vacuum vessel and the outer region, while the inner diffusive region resistivity is chosen to be ten times higher, i.s, rin $=10 \mathrm{r}$ out. These results show that the induced current changes very quickly only when the vacuum vessel resistivity is about $10^{-8} \Omega \mathrm{m}$.

The plasma equilibrium configurations were initially studied with the code GAEQ, disregarding the effects of structural eddy currents [5]. In that case a sequence of equilibrium configurations during the whole 10 second discharge was found and it was pointed out that $x$-point configurations could be easily obtained. In order to include the eddy current effects, the code PROTEUS is employed to study the plasma MHD equilibrium process of machine operation.

The Grad-Shafranov equation written as:

$$
\mathrm{L} \psi=\mathrm{j}_{\varnothing}
$$


with

$$
L=-\nabla^{*} \cdot\left(\frac{1}{\mu \mathrm{r}} \nabla^{*}\right), \quad \nabla^{*}=\varepsilon_{\mathrm{r}} \frac{\partial}{\partial \mathrm{r}}+\varepsilon_{\frac{z_{2}}{\partial z}}
$$

is solved in a semicircle large enough to encircle all the device in it. The toroidal current density $j \phi$ is

$$
j_{\phi}=r \frac{d p}{d \psi}+\frac{f}{r \mu_{0}} \frac{d i}{d \psi}=r c_{p}(1-\psi-2)+\frac{1}{f} c\left(1--^{2}\right)
$$

in the plasma, with

$$
\begin{gathered}
\bar{\psi}=\frac{\psi-\psi_{a}}{\psi_{b}-\psi_{a}}, \\
j_{\phi}=0
\end{gathered}
$$

in air, and

$$
\mathrm{j}_{\phi}=\frac{\sigma}{\mathrm{r}} \frac{\partial \psi}{\partial t}
$$

in the diffusive structures. In the PF coils and the virtual coils, $j_{\phi}$ is obtained from circuit equations with currents or voltages given.

In the equilibrium calculatiors for the low structural resistivity case, the total plasma current as a function of time evolves as shown in Figure 14. For the high resistivity case, the waveform is the same but without the one-second delay.

Because the code PROTEUS does not adjust the PF coil currents to find the desired equilibrium configurations, the equilibrium simulation for a whole discharge of about 10 seconds is rather complicated. In the high resistivity case, the code GAEQ is used first to find the proper PF coil currents for the desired configurations at several times throughout the 
discharge without eddy current effects. Then, the code PROTEUS is used to find the equilibrium configurations at the same time (small changes of the PF coil currents are considered since in PROTEUS the PF coils are modeled more accurately). Next, the entire set of equilibrium configuratic is is obtained without massive structures through interpolation for all input parameters. Then, a set of equilibria is found with eddy current effects included by perturbing the PF coil currents at the various times. In this way the desired equilibrium configuration sequence is found. The results show that the required PF coil currents are very close to the values given by the code GAEQ and that the effects of eddy currents are small.

In the low resistivity case, the effects of eddy currents are anticipated to be important so that the code GAEQ cannot be used as initialization. First the plasma is considered to be an active coil with current given. The appropriate flux surfaces in the vacuum vessel are obtained by step-by-step adjustments. The desired PF coil currents and eddy currents are obtained with code PROTEUS. Next, using those eddy currents, the proper equilibrium configurations are obtained for various times throughout the discharge by changing the PF coil currents. Then a set of equilibria is obtained in the same way as is done in the high resistivity case. The results of the Figure 15 correspond to the PF coil current evolution given by the solid line in Figures 6 to 13 and the plasma current shown in Figure 14.

For the high resistivity case the obtained equilibrium configurations are almost the same as that in Figure 15. However, in order to get such equilibria, the PF coil currents must be arranged as shown by the dotted lines in Figures 6 to 13.

It is obvious that the eddy current effects are significant in the low resistivity case. An important effect is that the current required in the PF coil \#1 is much lower in the low resistivity case than in the high resistivity case. Thus the current density and the stress is reduced in the IGNITEX configuration. Another calculation shows that the stress in coil \#1 is lower in the low resistivity case than in the high resistivity case even if the 
currents in the coil would be the same [11]. These results are important for the IGNITEX device from an engineering point of view. They should significantly reduce the cost and difficulty of construction of the machine.

In Figure 16, two configurations are shown. The first corresonds to the ase with virtual coil effects. The second corresponds to the case with PF coil currents only. Both configurations are shown at $t=5$ seconds. By comparing with Figure 15, the effects of either part of the structure can be seen.

\section{ANALYSIS OF THE POLOIDAL FIELD SYSTEM LEADS}

A poloidal field system [10] made of five pairs of coils and internal to the TF magnet is considered for IGNITEX. Figure 4 gives a sketch of the location of the poloidal field (PF) coils and TF magnet in a poloidal cross section of the device. For a high-current, elongated compact tokamak, an internal PF system has a number of advantages over other design options. Because the PF coils are close to the plasma column, the plasma shaping and control are facilitated. Thus, plasma equilibrium configurations along the discharge are easily obtained with and without accounting for the eddy currents self-sonsistently induced in the structures. In addition, $2-X$ point equilibrium configurations can be easily obtained, if desired. The PF system location also facilitates the control of vertical motion of the plasma and provides a high plasma-inductor coupling. Plasma coupling is further increased by including resistive shims around the plasma bore and a resistive layer around the PF system. Furthermore, locating the PF system inside the TF bore permits the use of the torus central hole space (typically occupied by the ohmic transformer) to place a high strength central bar, a configuration that increases the load-carrying capabilities of the TF magnet. Additional advantages are the reduction of overturning moments and the reduction of the PF power supply requirements. Assembly is facilitated by the single-turn design of each coil. Good operational flexibility is attained by having the five pairs of coils independently powered. Each PF coil is fed through a pair of parallel plate busbars in which the current flows in opposite directions so that they 
significantly self-cancel the magnetic fields that could locally perturb the field inside the plasma bore. The disturbance can be minimized by arranging the terminals in two poloidal cross sections $180^{\circ}$ apart so that flat terminals are possible. The leads are closely fitted in between TF plates and are completely encased by the TF magnet. A sketch of the terminals is shown in Figure 17.

Figure 18 gives the current pulse requirements for the IGNITEX PF and TF magnet systems. Ringing of the generators is employed to decrease the PF energy requirements, decrease magnet heating and decrease stresses in PF leads and coils. The lower current density then eases the design of the PF leads. It also reduces the perturbation of the vacuum magnetic field at start-up. HPG ringing technology is readily available. The total PF current swings from maximum at plasma breakdown (three seconds after the PF pulse begins) $+22 \mathrm{MA}$ to $-15.6 \mathrm{MA}$ at time $11 \mathrm{~s}$. The toroidal magnetic field is at its flat top from time $6 \mathrm{~s}$ to time $11 \mathrm{~s}$. The most critical time for the PF mechanical stresses due to the poloidal magnetic field is at plasma's breakdown. At this time, PF coils carry their maximum current and the plasma current is zero. Breakdown is also the worst time for the perturbation of the vacuum and plasma magnetic field due to stray fields caused by the PF terminals. However, due to the simultaneous ramping of plasma current and TF, the mechanical stresses on the PF leads due to toroidal iseld effects reach their maximum at the end of the flat top. Next, mechanical stresses on the PF coils (due to the poloidal field) and on the PF leads (due to the toroidal field) are calculated at breakdown and at the end of the flat top, respectively. Then the magnetic field perturbation due to the PF terminals is calculated at breakdown.

Electromagnetic stresses in the PF magnetic system are calculated with the finite elements code PROTEUS. Two different cases, with structural eddy current effects and without these effects, are considered. The plasma is simulated as an active coil with given current, filling up the vacum vessel. PF coils are active circuits with given currents. The vacuum vessel and the outer region of TF magnet are modeled as sets of passive circuits connected such that tht total current in either of them is 
zero. The inner region of TF coils is modeled as a diffusive area. The conductors in the circuits have the resistivity of copper at room temperature, and it is ten times that of copper in the diffusive part. The results are shown in Figure 19, where the von Mises stress in PF coil \#1 (which has the highest stress) is given in MKS units throughout the discharge for both cases.

In Figure 20, the lengths of the arrows are proportional to the von Mises stresses, and their direction represent the direction of the force acting upon the five PF coils located in the upper-half plane. The bases of the arrows are located in the center of each of the five PF coils. Figure 20a represents the case in which structural eddy currents are included. These results show that the maximum stress in the PF coils decreases significantly $(-30 \%)$ due to the existence of the structural conducting material. The maximum stress value is $320 \mathrm{MPa}$ (46ksi) at plasma breakdown.

The mechanical stresses in the PF leads due to the toroidal magnetic field are calculated in the lead of coil \#1 (see Figure 4). This lead carries the largest current and is located in the worst spot inside the TF magnet, which is in the center where the toroidal magnetic field reaches $32.8 \mathrm{~T}$. The stresses are maximum at the end of the flat top, eight seconds after breakdown. At this point the machine is operating at maximum magnetic field and at $70 \%$ of the maximum PF current. Total current in the lead is 2.2 MA. The current density in the PF lead is assumed uniform and perpendicular to the transverse cross section at each point. The current density in the TF magnet is considered uniform. A sketch of the copperalloy lead is given in Figure 21. It consists of a part which is embedded in the TF magnet, $35 \mathrm{~cm}$ wide, and a transverse part, $10 \mathrm{~cm}$ wide, that reaches out to the PF coil.

The structural analysis code ABAQUS [13] is used to calculate the maximum von Mises stress in the lead. In this calculation no displacement is allowed on the boundary of the part of the lead embedded in the TF magnet. Part of the stresses in the lead are relieved upon the TF magnet. 
For the transverse part, several boundary conditions are considered: 1) fixed boundary conditions are not imposed in the transverse part of the lead; 2) the transverse part of the lead is fixed in about half of its total length; 3) the whole transition, including the interface of the transition with the PF coil is fixed. The maximum von Mises stress are:

$\begin{array}{cc}\text { Case } & \text { Von Mises (ksi) } \\ 1 & 108 \\ 2 & 44 \\ 3 & 16\end{array}$

Case 2 has a stress below the yield strength ( $84 \mathrm{ksi}$ ) of the dispersion-strengthened copper. For case 1, beryllium copper will be appropriate. Figures 22a and $\mathrm{b}$ show the von Mises stress contours for cases 1 and 2, respectively. Calculations varying the dimensions of the embedded and transverse regions have been done. The width of the embedded region influences little the maximum stress value (due to the boundary condition used here). Stresses are strongly influenced by the width of the transverse part (up to a factor of two). The calculation in detail of the stress in the lead requires a more complete model in which both the TF magnet and the PF lead are fully included.

The effects of the PF terminal on the poloidal magnetic field configuration have been analyzed. Magnetic fields are calculated with the code EFFI. Figure 23 shows a cross section of the model on the PF coils and PF terminals used in this study. This is a simplified version of the actual geometry. The PF coils are made up of several current loops that approximate the eliptical shape of the actual IGNITEX coils. The PF leads are bar $\mathrm{s}, 5 \mathrm{~cm}$ wide. Every pair of leads feeding a coil occupy as much space as is available in the cross section. Coils \#2,3, and 5 are fed in the right side. Coils \#1 and 4 are fed in the left side. The actual shape of the leads will be modified based on both design considurations of the TF magnet as well as on the perturbed fields produced by the leads. Every coil is fed by a pair of parallel flat plates located close together. This 
model does not include the eddy currents induced in the structure of the device. The toroidal field and the plasma poloidal field are not included.

The magnetic field perturbation induced by the leads varies along the discharge because of the current swinging in the PF coils. Figure 24 gives the PF coil currents as a function of time when no structural eddy currents are taken into account. When eddy currents are present, the total current in the PF system is about the same but is more uniformly distributed between the five pairs of coils. At plasma breakdown, the current in coil \#1 varies from 3.745 MA to 4.75 MA with and without structural currents, respectively. Due to the limitations of the EFFI model, we use the PF currents given in Figure 24. This effect will cause the perturbation errors to be overestimated; especially so near the coils \#1 which is the more critica. The calculation presented here is done at the time of plasma breakdown. At later times, the perturbation is much smaller, in absolute terms, due to the reduction in the PF coil currents and in relative terms when compared to the poloidal field created by the plasma. Figures $25 \mathrm{a}, \mathrm{b}$ and $c$ give the magnitude of the total magnetic field. Figure 25a gives the unperturbed field. Figures $25 \mathrm{~b}$ and $\mathrm{c}$ give the total field in the cross section which contains the leads located at the right and at the left, respectively. The magnetic field has only the $z$ component in the $x, y$ plane. It has $x$ and $z$ components in the $x, z$ plane. Error fields obtained in this preliminary calculation are of the order of 500 gauss in the borders and of the order of 100 gauss near the plasma bore center with the maximum perturbation located in the proximity of coil \#1. The values of the perturation obtained with this EFFI model are very sensitive to the specific detail of the current density in leads and coils, especially in the vicinity of the joints of the leads with the coils. A difference of hundreds of gauss can be obtained by modification of the current density. The definitive results will be calculated with a detailed 3-D geometric model. After the detailed study is done, modifications in the design of the terminals will be considered, as appropriate.

As pointed out above, the field perturbation due to the PF leads during the flat top of the discharge is negligible. There are other 
perturbations due to the TF magnet design with a periodcity of $n=12$ that need to be taken into account. These perturbations inight be produced by the separation of the TF single-turn magnet in 12 sectors fed by independent HPG's. The IGNITEX device has favorable characteristics for alpha particle confinement: high field, high current, low $q$ and small alpha Larmor radius. It has a high ripple threshold value for alpha particle loss due to stochastic ripple losses, the potentially most dangerous loss mechanism. Alpha transport simulations using single orbit models 14 give negligible alpha loses with high-n ripple levels up to $4 \%$. Threshold levels for low-n ripple are even higher. Good alpha particle containment is critical to reach and sustain ignition. At flat top the TF current density will be homogenized and the ripple due to the TF magnet is expected to be low. Plasma breakdown by inductive means requires a level of field perturbation low enough to allow the electrons to run around the tokamak until a cascade is established. For the IGNITEX experiment, breakdown due to resonant cavity modes is being considered. This breakdown method has several potential advantages such as reduction of the magnetic flux requirement, induction of breakdown at higher densities, and reproducibility. It also has the potential advantage of a reduction in the length required for breakdown.

\section{CONCLUSIONS}

The results of the work reported here confirm the potential of the IGNITEX experiment as a way to produce and control fusion ignition for scientific study in a relatively simple and low cost way. The preceding sections summarize the work performed under this grant in the areas of:

. structural eddy currents effects on plasma squilibrium,

- alpha-particle containment, and

- analysis of the poloidal field system leads. 
The following system of state-of-the-art codes have been fully implemented for the IGNITEX design and analysis in the course of the reported work:

- Eddy-current effects in plasma equilibrium: GAEQ, PROTEUS

- Alpha-particle transport: DESORB, RIPLOS

- Poloidal field system leads: EFFT, ABAQUS

Some 19 publications have been partially funded by this grant. Some 28 presentations have been partially funded by this grant. These publications and presentations have been included in the Appendix. The presentations include two talks, to the Ignition Technical Oversight Committee, one talk in a Fusion Power Associates Symposium, and two reviews by Office of Energy personnel held at The University of Texas at Austin. Finally, partially because of the support of this grant a proposal for the preliminary design of the fusion ignition experiment (IGNITEX) and for a generator technology demonstration (for $\$ 11 \mathrm{M} / 2.5$ years) has been presented to the Office of Fusion Energy of the US Department of Energy. Next some conclusions of the work in this proposal are highlighted.

Using the 2-D finite element code PROTEUS, the plasma current induction and MHD equilibrium with structural eddy current effects included have been studied for the IGNITEX experiment. The results show that the flux swing provided by the PF coil currents is enough to induce $12 \mathrm{MA}$ plasma current in a pulse of 10 seconds. A complete set of equilibrium configurations is obtained throughout the discharge with the plasma surface very close to and having almost the same shape as the vacuum vessel during the flat-top plasma current period. It is seen that a limiterless discharge is possible if the plasma position and shape are controlled properly by a feedback system. Since the PF coils are adjacent to and have strong coupling with the plasma, such control should be effective. 
The plasma current induction is delayed about one second because of the eddy current effects. The distribution of the current in the PF magnet system required for obtaining the desired MHD equilibrium configurations is changed significantly by the conducting structures, in particular, the maximum current in PF coil \#1 is decreased. This should relieve stresses and heating and decrease costs.

An internal PF system as used in the IGNITEX machine provides: good plasma equilibrium for high current discharges; high plasma coupling; good plasma control; ease of plasma shaping; higher TF magnet strength (by use of control compression post); decrease of overturning moments, and decrease of PF power requirements. The massive TF structure serves to reduce the PF stresses by the global effect of the induced structural eddy currents and peak stresses in the PF magnet system are further decreased by the TF structure effects, that made the current distribution in the PF system more uniform than in the case in which no massive structures are present. A single-turn coil PF design, fed by homopolar generator power supplies, should provide ease of assembly.

Alpha transport has been studied in detail. It has been seen that in IGNITEX the alpha-particle Larmour radius is so small $(1.3 \mathrm{~cm})$ and the plasma current so large (12 MA) that rather good alpha containment is to be expected. Because of the single-turn, compact nature of the TF magnet, negligible high-n ripple will be produced in IGNITEX. However, guiding center motion simulations indicate that ripples over $4 \%$ would be tolerable without significant detriment of alpha heating for the plasma. Low-n ripple could be present in IGNITEX, for example, through the failure of one TF generator or induced by the PF leads. However, the IGNITEX experiment has a high threshold condition on the ripple strength for stochastic ripple losses (the most dangerous loss mechanism), specially for $\mathbf{n}=2$ ripple sources. Therefore, it is concluded that high alpha containment will be obtained in IGNITEX on the basis of present understanding. 
Some conclusions can be derived from the preliminary analyses of several aspects of the design and operation of the PF system of the IGNITEX experiment. Stresses on the PF system due to the poloidal field are calculated along the discharge for unsupported coils. When the full structure of the TF magnet which surrounds the PF magnet system is included, the maximum von Mises stress is reduced by about $30 \%$ to $46 \mathrm{ksi}$. Stresses on the PF terminals due to the toroidal field are also calculated. The maximum stress is located in lead \#1, and occurs at the end of the flat top part of the discharge. The lead is assumed to be partially embedded in the TF magnet material. Several cases with different boundary conditions are considered. A model that fully takes into account the PF terminal, TF magnet, and their interface, will be considered as part of a more detailed design. The maximum stress obtained in the PF terminals varies from 44 ksi to $108 \mathrm{ksi}$, depending on the level of encasement of the transverse part of the lead \#1 in the TF magnet. The maximum stress of $108 \mathrm{ksi}$ can be tolerated by a terminal fabricated with beryllium-copper alloy. An ample room for design improvement is foreseen.

Another aspect considered in some detail is the perturbation of the vacuum magnetic field structure at breakdown due to the influence of the PF terminals. Using a simplified model of the geometry of the leads and coils, the perturbation of the vacuum magnetic field in the center of the plasma bore is about 100 gauss. When the current in the PF coils is at a maximum, the highest field perturbation is located inside the PF coil \#1. The model does not include structural eddy currents which are known to reduce the current in the lead $\# 1$ and then, equilibrium perturbation. The value of the magnetic field perturbation is very sensitive to the current density profile used, especially in the portion of material where the leads join the PF coils. It also can be altered by varying the space occupied by the flat terminal plates. A more detailed analysis is needed with more accurate current density distribution in leads and coils. Design modifications will be considered to minimize the perturbed fields at plasma breakdown. During the ramp up and flat top part of the discharge, the field perturbation is smaller in absolute terms, due to the decrease in the PF coil current, and also in relative terms due to the presence of the plasma 
current. The proposed resonant cavity mode assisted breakdown should be taken into account to decide the level of perturbation that can be tolerated.

A controlled self-sustained fusion reaction is a new basic physics process that could be produced and studied in the near future with a tokamak device.

A simple, theoretically reliable, and low cost ignition experiment requires a tokamak with about twice the magnet field conventionally available.

The iGNITEX concept provides a way of performing an ignition experiment in the near term with relatively benign environmental characteristics.

The IGNITEX experiment can provide a relatively low cost research tool for the study of thermonuclear plasmas.

The IGNITEX experiment should demonstrate controlled fusion in a iaboratory. In the experiment fusion power densities comparable to those of fission power systems should be produced. The study of ignited plasmas will be possible. Scaling laws at ignition should be obtained from data produced in the experiment's discharges. The development of fusion control techniques will be possible. Also the heating of more advanced fuels by the alpha-particles generated during the deuterium-tritium ignition will become feasible. 


\section{REFERENCES}

1. M.N. Rosenbluth, W.F. Weldon, an d H.H. Woodson, "Basic Design Report of the Fusion Ignition Experiment (IGNITEX)," Center for Fusion Engineering, The University of Texas at Austin, March, 1987.

2. R. Carrera and W.F. Weldon, "Proposal to the US Department of Energy for the Preliminary Design of the Fusion Ignition Experiment (IGNITEX) and for a Generator Technology Demonstration," Center for Fusion Engineering, The University of Texas at Austin, March, 1989.

3. K.T. Hsieh, M.D. Driga, W.F. Weldon, and M.D. Werst, "Electromechanical Analysis of a Prototype 20 Tesla, Single Turn Toroidal Field Coil for IGNITEX", 13th International Symposium on Fusion Engineering, Knoxville, TN (October, 1989) and M.D. Werst, G.W. Brunson, M.D. Driga, K.T. Hsieh, R.L. Sledge, W.F. Weldon, and H.H. Woodson, "Design of a Prototype 20 Tesla, Single Turn, Toroidal Field Coil for the Fusion Ignition Experiment (IGNITEX)", i3th International Symposium on Fusion Engineering, Knoxville, TN (October, 1989).

4. F.J. Helton, J.W. Helton, and J.M. Greene, "On Necessary Equilibrium Conditions for Advanced Toroidal Plasma Experiments", GA Technologies Inc. Report (1987).

5. E. Montalvo, R. Carrera, M.N. Rosenbluth, and J.W. Van Dam, Plasma "Equilibrium during Ignition in Single-Turn Coil Tokamak", Bull. Am. Phys. Soc., 32, 1923, (1987).

6. L.L. Lao, R.M. Wieland, W.A. Houlberg, and S.P. Hirshman, "VMONS: A Computer Code for Finding Moment Solutions to the Grad-Shafranov Equation", Comput. Phys. Commun., 27, 129, (1982). 
7. F.J. Helton, and T.S. Wang, "MHD Equilibrium in Non-Circular Tokamaks with Field-Shaping Coil Systems", Nuclear Fusion, 18, 1523, (1978).

8. R. Albanese, J. Blum, and O. DeBarbieri, "On the Solution of the Magnetic Flux Equation in an Infinite Domain", 8th Europhysics Conference on Computational Physics, Eibsee, Vol. 10D, 41, (May, 1986).

9. L.M. Hively, "TF-Ripple Losses from a Non-Circular Tokamak", Nuclear Fusion, 24, 779, (1984).

10. M.D. Driga, W.F. Weldon, H.H. Woodson, W.A. Walls, and K.T. Hsieh, "Magnet System for the IGNITEX Fusion Ignition Experiment", 12th Symposium on Fusion Engineering, Monterey, Calif., Vol. 1, 322, (October, 1987).

11. E. Montalvo, R. Carrera, J. Dong, M. Driga, K. Hsieh, W. Walls and W. Weldon, "Analysis of the Poloidal Field System Leads in the IGNITEX Experiment," paper presented at the 13th International Symposium on Fusion Engineering, October 2- 6, 1989.

12. W.A. Walls, W.F. Weldon, H.H. Woodson, M.D. Driga, and J.H. Gully, "Pulsed Homopolar Generator Power Supplies for the IGNITEX Experiment," 12th Symposium on Fusion Engineering, Monterey, CA, 1, 460, October, 1987.

13. Hibbit, Karlsson and Sorensen, Inc., 100 Medway Street, Providence, RI 02906.

14. E. Montalvo, R. Carrera, L. Hively, and M.N. Rosenbluth, "Equilibrium Analysis and Alpha Containment in the Ignition Experiment (IGNITEX)," Bull. Ann. Phys. Soc., 33, 1970, October, 1988. 


\section{APPENT IX}

\section{IGNITEX PUBLICATIONS PARTIALLY FUNDED BY THIS GRANT}

1) R. Carrera, M. D. Driga, J. H. Gully, N. E. Hertel, J. Hopf, K. T. Hsieh, E. Montalvo, C. Ordonez, T. Parish, M. N. Rosenbluth, W. A. Walls, W. F. Weldon, M. Werst, and H. H. Woodson, Ignition Experiment in a Single-Turn-Coil Tokamak, 8th Topical Meeting on the Technology of Fusion Energy, Salt Lake City, Utah (Oct. 1988); Fusion Technology 15, 402 (1989).

2) IGNITEX Group, IGNITEX Experiment, Bull. Am. Phys. Soc. 33, 2044 (October 1988).

3) E. Montalvo, R. Carrera, L. Hively, and M. N. Rosenbluth, Equilibrium Analysis and Alpha Containment in the Ignition Experiment (IGNITEX), Bull. Am. Phys. Soc. 33, 1970 (October 1988).

4) R. Carrera and W. F. Weldon, Proposal to the US Department of Energy for the Preliminary Design of the Fusion Ignition Experiment (IGNITEX) and for a Generator Technology Demonstration, Center for Fusion Engineering Report (March 1989).

5) R. Carrera, G. Y. Fu, J. Helton, L. Hively, E. Montalvo, C. Ordonez, M. N. Rosenbluth, S. Tamor, and J. W. Van Dam, Analysis of the Ignition Experiment IGNITEX, Proceedings of the 16th European Conference on Controlled Fusion and Plasma Physics, Venice, Italy, 1, 375 (March 1989).

6) R. Carrera, G. Fu, J. Helton, L. Hively, E. Montalvo, C. Ordonez, M. Rosenbluth, S. Tamor, and J. Van Dam, Plasma Physics Considerations in the Fusion Ignition Experiment IGNITEX, Controlled Fusion Theory Conference (International Sherwood Theory Meeting), San Antonio, TX, 2D2 (April 1989).

7) R. Carrera, Creation of Compact, High-Power Density Fusion Plasmas in the IGNITEX Device, Journal of Fusion Energy, Vol. 8, Nos. 1-2, 31 (1989).

8) R. Carrera, M. Barrington, R. Bickerton, W. D. Booth, Y. Chen, J. Dong, M. Driga, S. Eways, G. Fu, J. Gully, G. Hallock, J. Helton, N. Hertel, L. Hively, J. Howell, K. Hsieh, J. Ling, G. Miller, E. Montalvo, C. Ordonez, D. Palmrose, T. Parish, M. Rosenbluth, S. Tamor, D. Tesar, J. 
Van Dam, P. Varghese, A. Walls, W. Weldon, M. Werst, and H. Woodson, IGNITEX Experiment, 16th IEEE International Conference on Plasma Science, Buffalo, New York, IEEE 89-CH-2760-7, 58 (May 1989).

9) G. Fu, R. Bickerton, R. Carrera, J. Dong, J. Helton, L. Hively, E. Montalvo, C. Ordonez, M. Rosenbluth, S. Tamor, and J. Van Dam, Ohmic and Alpha Heating in the High-Field IGNITEX Tokamak, 16th IEEE International Conference on Plasma Science, Buffalo, New York, IEEE 89CH-2760-7, 157 (May 1989).

10) S. Eways, R. Carrera, J. Dong, G. Hallock, and E. Montalvo, Operation of the IGNITEX Tokamak, 16th IEEE International Conference on Plasma Science, Buffalo, New York, IEEE 89-CH-2760-7, 159 (May 1989).

11) IGNITEX Group, Basis, Description, and Objectives of the IGNITEX Experiment, 13th International Symposium on Fusion Engineering, Knoxville, TN (October 1989).

12) E. Montalvo, R. Carrera, G. Y. Fu, J. Helton, L. Hively, H. Howe, C. Ordonez, M. N. Rosenbluth, D. Sigmar, S. Tamor, and J. Van Dam, Fusion Physics Study of the IGNITEX Experiment, 13th International Symposium on Fusion Engineering, Knoxville, TN (October 1989).

13) J. Dong, E. Montalvo, R. Carrera, and M. N. Rosenbluth, Structural Eddy Current Effects on Plasma Equilibrium and Current Induction in the IGNITEX Experiment, 13th International Symposium on Fusion Engineering, Knoxville, TN (October 1989).

14) E. Montalvo, R. Carrera, K. Hsieh, and W. Weldon, Analysis of the Poloidal Field System Leads in the IGNITEX Experiment, 13th International Symposium on Fusion Engineering, Knoxville, TN (October 1989).

15) R. Carrera, G. Y. Fu, L. Hively, G. Miley, E. Montalvo, M. N. Rosenbluth, D. Sigmar, S. Tamor, and J. Van Dam, Preliminary Analysis of Alpha Particle Effects in the Fusion Ignition Experiment IGNITEX, Alpha Particle Confinement and Heating IAEA Meeting, Kiev, USSR (October 1989).

16) IGNITEX Group, Fusion Physics Analysis of the IGNITEX Experiment, 31st Annual Meeting of the APS (Div. Plasma Physics), Anaheim, CA (November 1989). 
17) R. Carrera, G. Y. Fu, L. Hively, G. Miley, E. Montalvo, M. N. Rosenbluth, D. Sigmar, S. Tamor, and J. Van Dam, Description of Alpha Physics Phenomena in the IGNITEX Experiment, 31st Annual Meeting of the APS (Div. Plasma Physics), Anaheim, CA (November 1989).

18)) E. Montalvo, J. Q. Dong, R. Carrera, J. Helton, and M. N. Rosenbluth, Study of the Poloidal Field System in the IGNI'rEX Experiment with Eddy Current Effects, 31st Annual Meeting of the APS (Div. Plasma Physics), Anaheim, CA (November 1989).

19) J.Q. Dong, E. Montalvo, R. Carrera, J. Helton, and M.N. Rosenbluth, Vertical Stability and Plasma Equilibrium in the IGNITEX Experiment, 31st Annual Meeting of the APS (Div. Plasma Physics), Anaheim, CA (November 1989)

\section{IGNITEX PRESENTATIONS PARTIALLY FUNDED BY THIS GRANT}

1) DOE Ignition Technical Oversight Committee, University of California, San Diego, August 1988, "Resolution of IGNITEX Technical Problems" (R. Carrera).

2) Panel Discussion on Compact Tokamak Ignition Concepts, Fusion Power Associates Annual Meeting and Symposium on Creating Compact, High-Power Density Fusion Plasmas, Santa Fe, September 1988, Creation of Compact, High-Power Density Fusion Plasmas in the IGNITEX Device, (R. Carrera); "High-Field, Single-Turn, Magnet Technology for IGNITEX (W. F. Weldon).

3) Los Alamos National Laboratory, Los Alamos, New Mexico, September 1988, "Magnetic Fusion Ignition Experiment" (R. Carrera).

4) Physics Department, The University of Texas at Austin, September 1988, "Scientific and Technological Basis for the Fusion Ignition Experiment IGNITEX ${ }^{n}$ (R. Carrera).

5) Eighth Topical Meeting on the Technology of Fusion Energy, Salt Lake City, Utah, October 1988, "Ignition Experiment in a Single-TurnCoil Tokamak" (R. Carrera).

6) Thirtieth Annual Meeting of the Division of Plasma Physics of the American Physical Society, Hollywood, Florida, November 1988, "IGNITEX Experiment" (R. Carrera). 
7) US DOE-sponsored IGNITEX Project Review, The University of Texas at Austin, December 1988, "Introduction" (R. Carrera), "Description of the Experiment" (R. Carrera), "Analysis of Physics Questions Relevant to the IGNITEX Experiment" (E. Montalvo), "Magnet and Power Supply Systems" (A. Walls), "IGNITEX Technology Demonstrator" (M. Werst), "Nuclear Radiation Analysis" (T. Parish), "Diagnostics and Experimental Program for IGNITEX (W. D. Booth), "Breakdown and Operation" (G. Hallock), "First-Wall System Design" (P. Varghese), "Considerations for the Maintenance of the IGNITEX Experiment" (M. Barrington), "Conclusions" (R. Carrera).

8) Soviet Fusion Delegation Meeting, The University of Texas at Austin, January 1989, "Plasma Physics, Electromechanics, and Nuclear Engineering Aspects of the IGNITEX Experiment" (R. Carrera); "Ignition Technology Demonstration for IGNITEX" (W. F. Weldon).

9) DOE Ignition Technical Oversight Committee, University of California, San Diego, February 1989, "IGNITEX Coil Studies" (R. Carrera).

10) Lawrence Livermore National Laboratory, Livermore, California, February 1989, "The Fusion Ignition Experiment IGNITEX" (R. Carrera).

11) CEN, Comissariat d'Energie Atomique. Cadarache, France, March 1989, "Ignition in a Single-Turn Tokamak" (R. Carrera).

12) ETSIl, Polytechnic University of Madrid, Madrid, Spain, March 1989, "Experiment to Produce and Control Fusion Ignition" (R. Carrera).

13) CIEMAT, Spanish Nuclear Agency, Madrid, Spain, March 1989, "Fusion Ignition Experiment, IGNITEX" (R. Carrera).

14) Massachusetts Institute of Technology, Cambridge, Massachusetts, April 1989, "Fusion Ignition in a Single-Turn Tokamak" (R. Carrera).

15) Princeton Plasma Physics Laboratory, Princeton, New Jersey, April 1989, "The Ignition Experiment, IGNITEX" (R. Carrera).

16) Oak Ridge National Laboratory , Oak Ridge, TN, April 1989, "Description of a Fusion Ignition Experiment" (R. Carrera).

17) Texas A \& M University, Nuclear Engineering Department, College Station, May 1989, "Conceptual Design of the IGNITEX Experiment" (R. Carrera). 
18) Physics Department, The University of Texas at Austin, May 1989, "Description of the Ignition Experiment IGNITEX" (R. Carrera).

19) 16th IEEE International Conference on Plasma Science, Buffalo, New York, May, 1989, "IGNITEX Experiment" (R. Carrera).

20) CFFTP, Mississauga, Ontario, Canada, May 1989, "Low Cost Fusion Ignition Experiment in a Single-Turn Tokamak" (R. Carrera).

21) GA Technologies, Inc., San Diego, California, June 1989, "Physics and Engineering Aspects of the IGNITEX Experiment" (R. Carrera).

22) CEM, Balcones Research Center, The University of Texas at Austin, July 1989, "The Fusion Ignition Experiment IGNITEX" (R. Carrera).

23) US Department of Energy Review of the IGNITEX Project and Proposal, Balcones Research Center, The University of Texas at Austin, September 1989, "IGNITEX Project" (R. Carrera), "IGNITEX Experiment" (R. Carrera), "Physics Study" (E. Montalvo), "Electromechanics System" (W. A. Walls), "Operation" (J. Q. Dong), "Breakdown" (S. Eways), "Activation and Environment" (T. A. Parish), "First Wall System" (G. Rodin), "Diagnostic Design" (D. Booth), "Costs and Design Considerations" (R. Carrera), "Ignition-Technology Demonstration Program" (W. F. Weldon), "Single-Turn-Coil Magnet Technology Demonstration" (M. Werst), "IGNITEX Proposal (Preliminary Design of the Fusion Ignition Experiment IGNITEX)" (R. Carrera), "IGNITEX Proposal (Generator Technology Demonstration)" (W. F. Weldon).

24) 13th International Symposium on Fusion Engineering, Knoxville, TN, October 1989, "Basis, Description, and Objectives of the IGNITEX Experiment" (R. Carrera).

25) I. V. Kurchatov Institute of Atomic Energy, Moscow, USSR, October 1989, "Ohmic Fusion" (R. Carrera).

26) I. V. Kurchatov Institute of Atomic Energy, Troitsk, USSR, October 1989, "IGNITEX Experiment" (R. Carrera).

27) Institute for Nuclear Research, Academy of Sciences of the Ukrainian SSR, Kiev, USSR, October 1989, "Analysis of Alpha Particle Effects in the Fusion Ignition Experiment IGNITEX" (R. Carrera). 
28) 31st Annual Meeting of the APS (Div. Plasma Physics), Anaheim, CA, November 1989, "Fusion Physics Analysis of the IGNITEX Experiment" (R. Carrera). 


\begin{tabular}{|c|c|c|c|}
\hline Table 1 & & IGNI & EX Project Schedule \\
\hline $6 / 86$ & to & $7 / 88$ & Basic physics and electromechanics \\
\hline $8 / 88$ & to & $9 / 89$ & $\begin{array}{l}\text { Conceptual Design } \\
\text { ITD (TF magnet demonstration) }\end{array}$ \\
\hline $10 / 89$ & to & $9 / 91$ & $\begin{array}{l}\text { Preliminary design } \\
\text { ITD (generator demonstration) }\end{array}$ \\
\hline $10 / 91$ & to & $9 / 92$ & $\begin{array}{l}\text { Detailed design } \\
\text { ITD (PF magnet demonstration) }\end{array}$ \\
\hline $10 / 92$ & to & $9 / 95$ & Construction Commissioning \\
\hline Octobe & 1925 & & Experiment Operation \\
\hline $10 / 95$ & to & $9 / 96$ & H Phase of operation \\
\hline 10966 & to & $4 / 97$ & D Phase of operation \\
\hline May 19 & & & DT Operation \\
\hline $5 M 7$ & to & $9 / 98$ & T Phase of operation \\
\hline
\end{tabular}


Table 2 IGNITEX Areas of Work

\section{FUSION PHYSICS}

ELECTROMECHANICS

FUSION ENGINEERING

1. Ignition margin

2. Simulation

3. Equilibrium

4. Stability

5. Transport

6. Kinetics

7. Thermal Runaway

8. Confinement Degradation

9. Radiation

10. Transients
Ignition Technology

Demonstration (Magnet HPG)

Single-Turn Coil

Internal Inductor

Vessel
Radiation

Tritium System

Environment

First Wall-Design

-Materials

-Maintenance
Structure

Magnet Fabrication

Power Supply

Circuitry

Precooling

Pellet injector
Diagnostics

Vacuum-Fueling

Operation

Structures-Facilities 
Table 3 IGNITEX Experiment

Minor radius $\quad 47 . \quad \mathrm{cm}$

Major radius $\quad 150 . \quad \mathrm{cm}$

$\begin{array}{lrl}\text { Plasma elongation } & 1.6 & \\ \text { Toroidal field on axis } & 20.2 & T\end{array}$

Safety factor at the

plasma edge $\quad 27.2$

Plama current 12.2 MA

Avg. plasma density $\quad 3.6 \times 10^{14} \mathrm{~cm}^{-3}$

Avg. plasma temperature $\quad 6.5 \quad \mathrm{keV}$

$\begin{array}{lll}\text { Avg. toroidal beta } & 0.6 & \%\end{array}$

Avg. energy confinement

time 0.54

Confinement product

Ignition margin (KG)

Fusion power

Neutron wall load

Neutron prochuction rate

Alpha contaimment factor

nOtETO product

$3.9 \times 10^{14} \mathrm{~s} / \mathrm{cm}^{-3}$

3.4

149.

3. $\mathrm{Mw} / \mathrm{m}^{2}$

$5.3 \times 10^{19} \mathrm{n} / \mathrm{s}$

3.2

$4.7 \times 10^{15} \mathrm{keV} . \mathrm{s} / \mathrm{cm}^{3}$ 
Table 4 Estimated Cost Breakdown of the IGNITEX Experiment

Title

Cost

(\$ million)

First wall

Vacuum vessel

PF coil system

1.5

2.5

4.2

Single-turn TF coil

Cryogenics

TF coil support structure

30.0

2.3

7.5

Remote maintenance

3.0

Shielding

TF power supply

PF power supply

Diagnostics

1.0

38.4

8.2

2.9

Vacuum pumping

Fueling

Disposal

0.9

0.5

3.0

Instrumentation and control

Facility

Project

3.0

8.0

13.0

Estimated Cost (in millions) $\$ 129.9$ 


\section{TOROIDAL FIELD COIL SYSTEM}

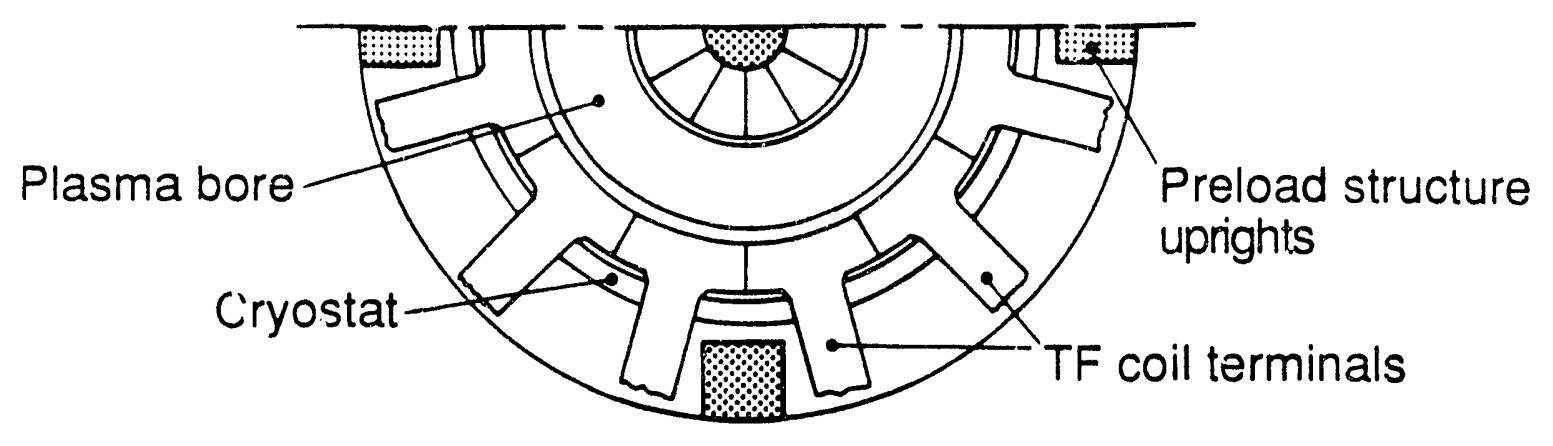

TF coil preload and support structure Hydraulic press

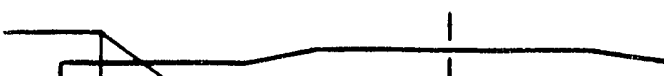




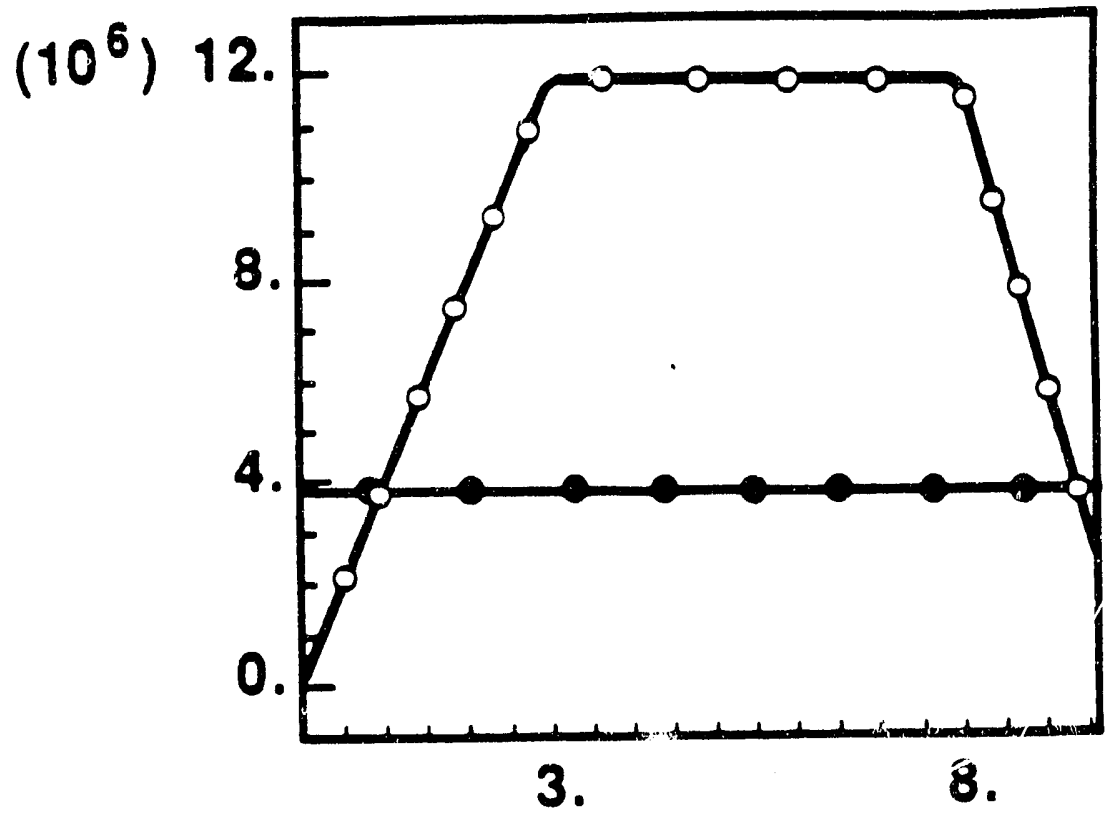

PLASMA CURRENT (AMP) -V3- TIME (SEC) $O=$ PLASMA CURRENT $0=$ MINIMUM CURRENT FOR ALPHA CONFINEMENT

Figure 2 IGNITEX current puise. 


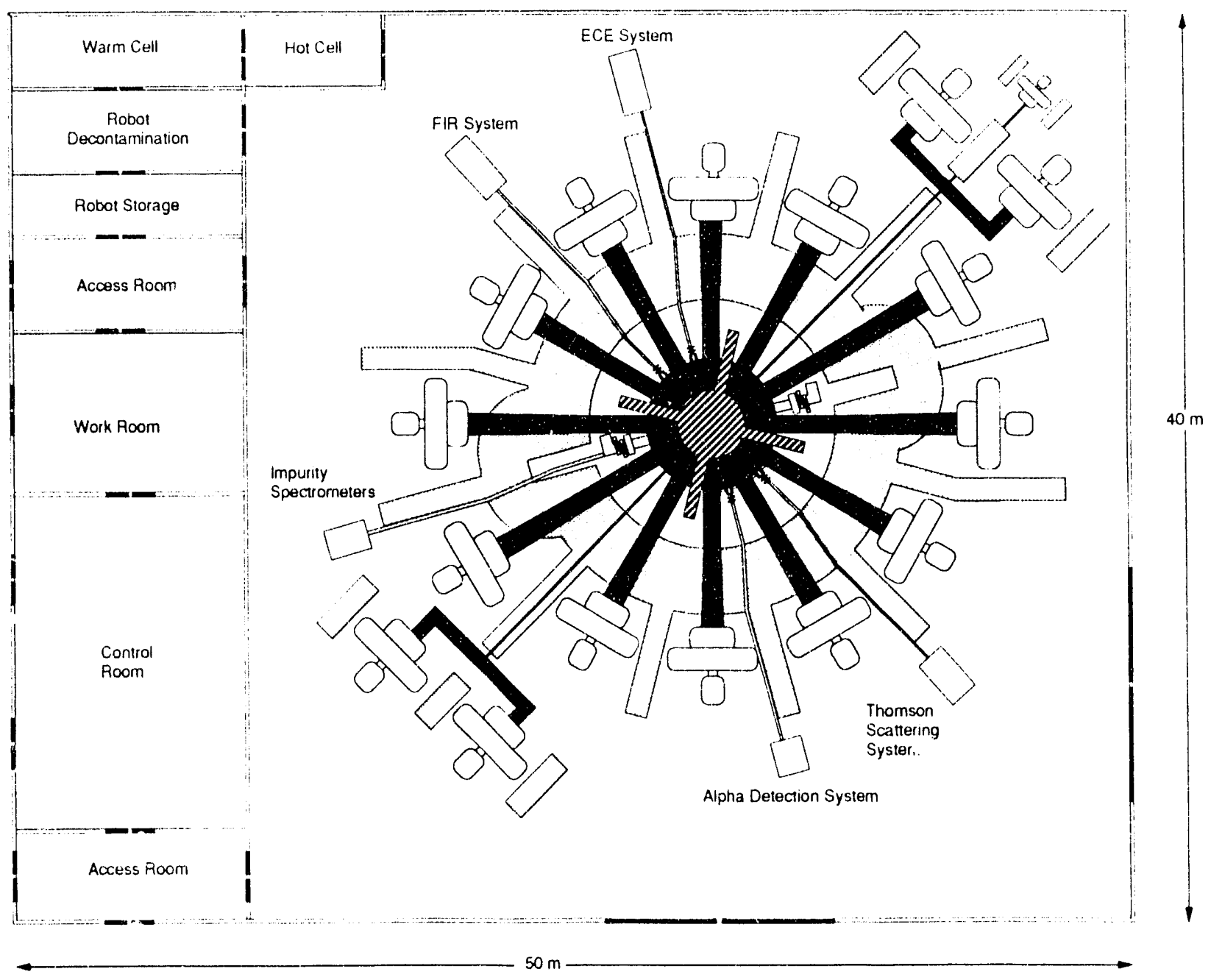

Figure 3 IGNITEX Machine Conceptual Leved Floor Plan. 


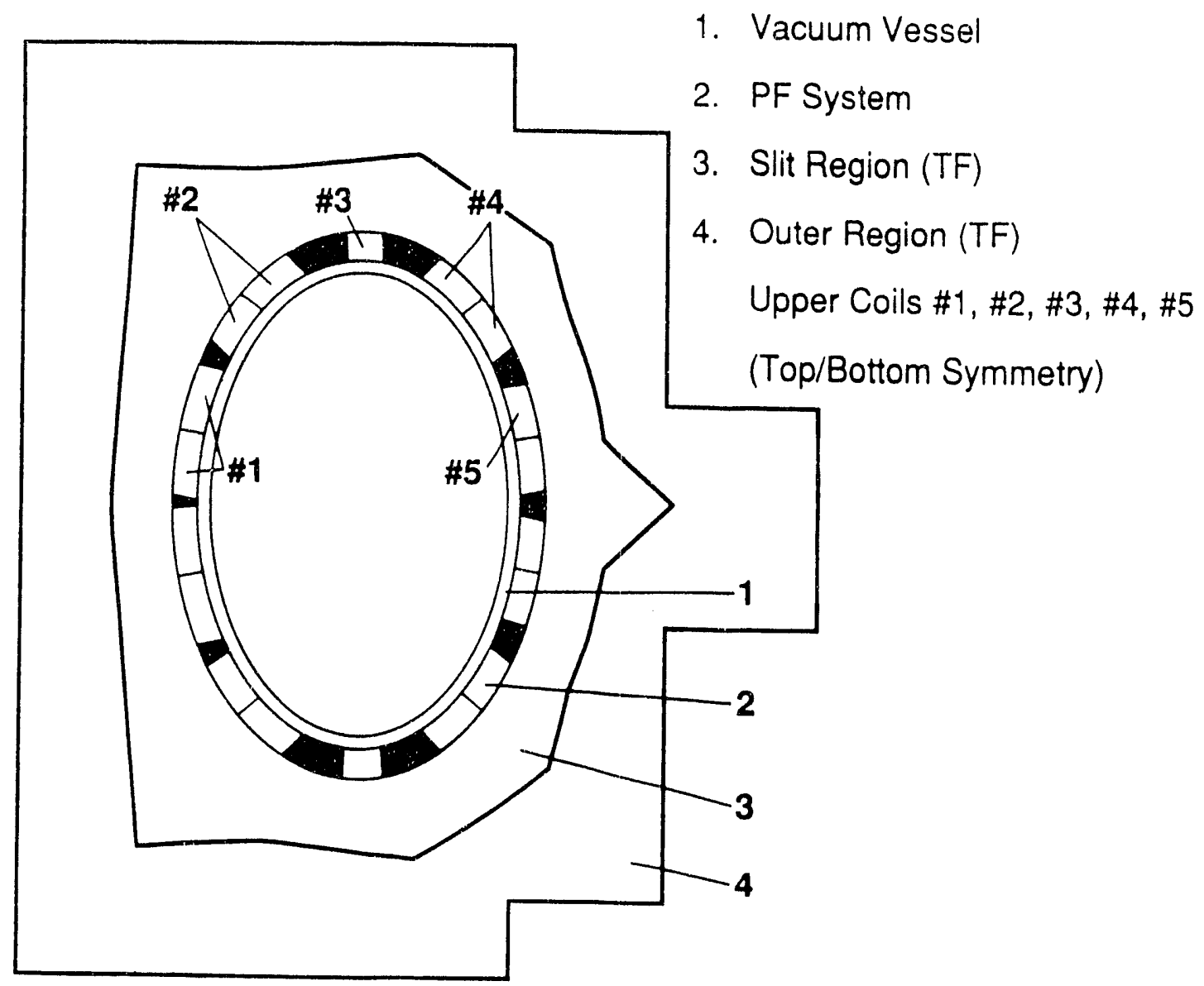

Figure 4 Poloidal cross section of the IGNITEX Experiment. 


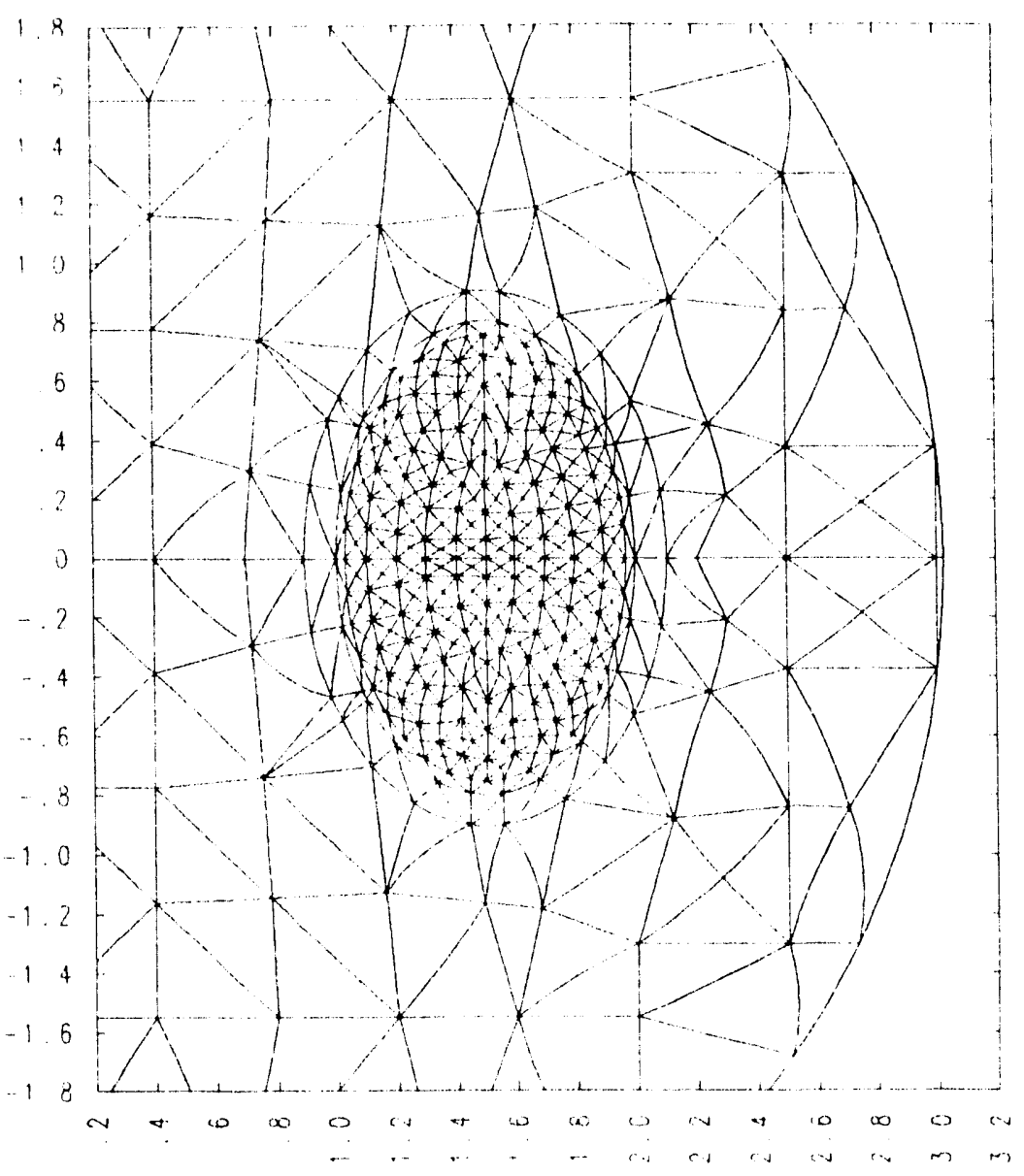

Figure 5 Main part of the finite element grid used for the IGNITEX device. 


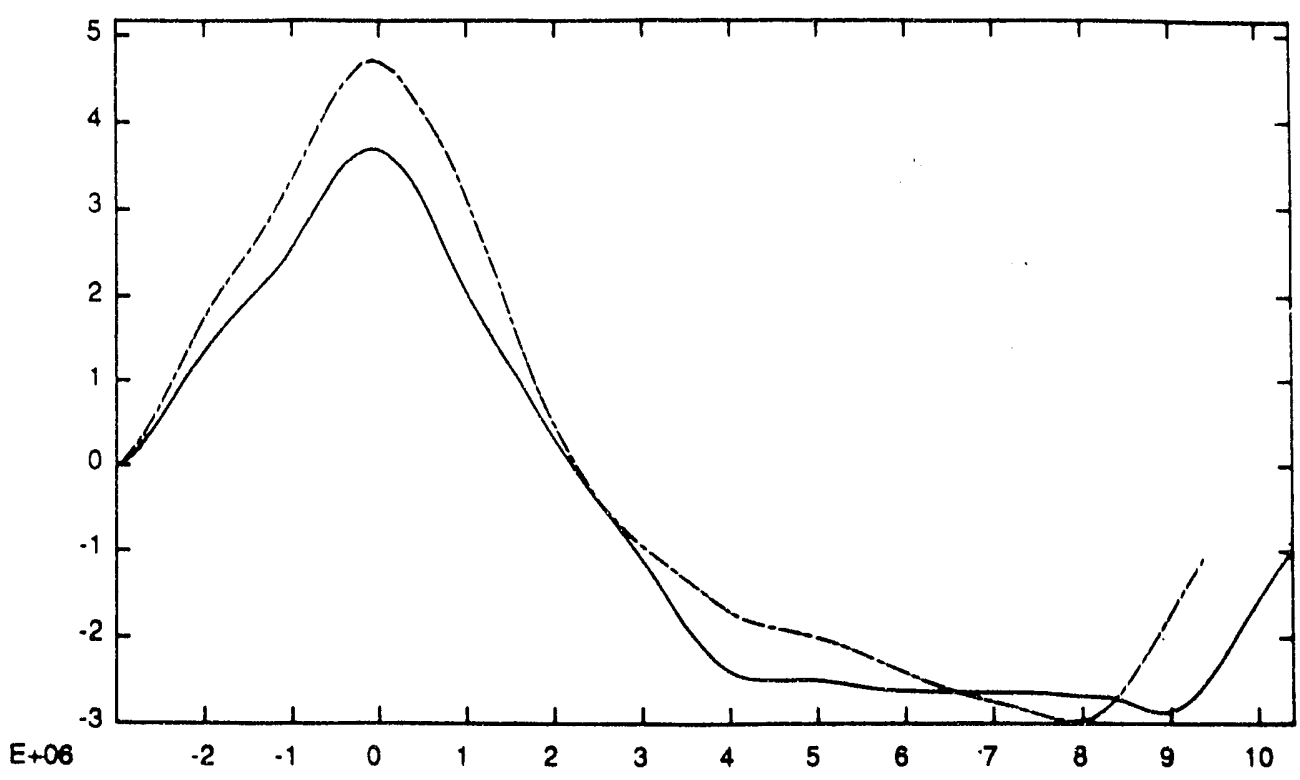

Figure 6. Current in PF coil \#1 as function of time.

Solid line - low resistivity case

Dotted line - high resistivity case

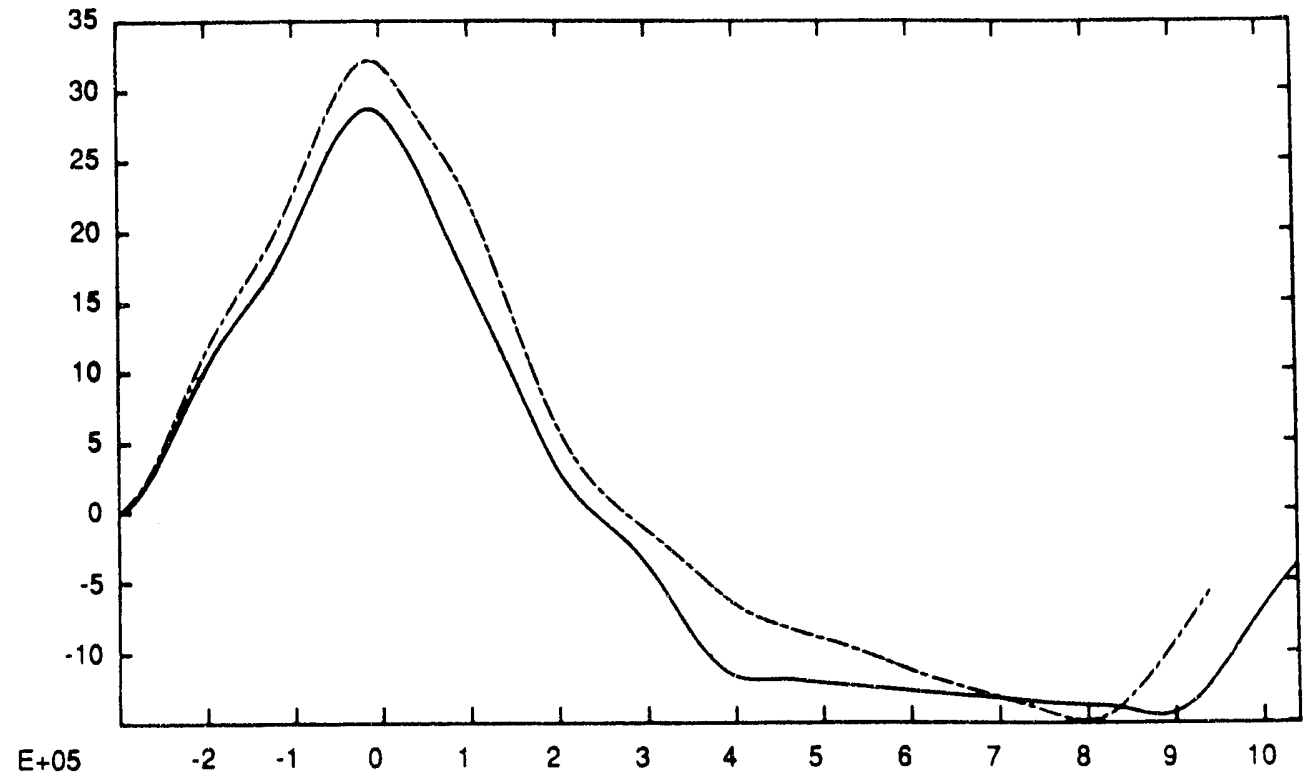

Figure 7 Current in PF coil \#2 as function of time.

Solid line - low resistivity case

Dotted line - high resistivity case 


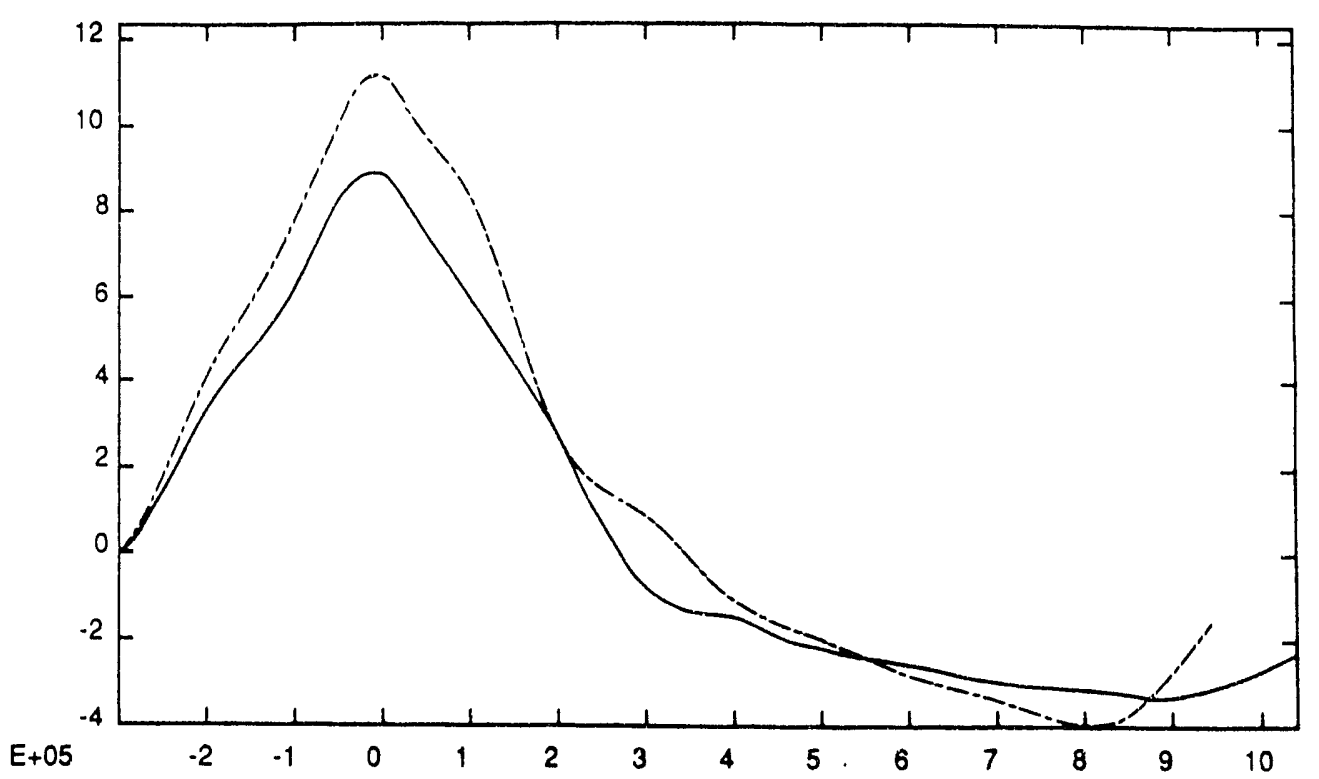

Figure 8 Current in PF coil \#3 as function of time.

Solid line - low resistivity case

Dotted line - high resistivity case

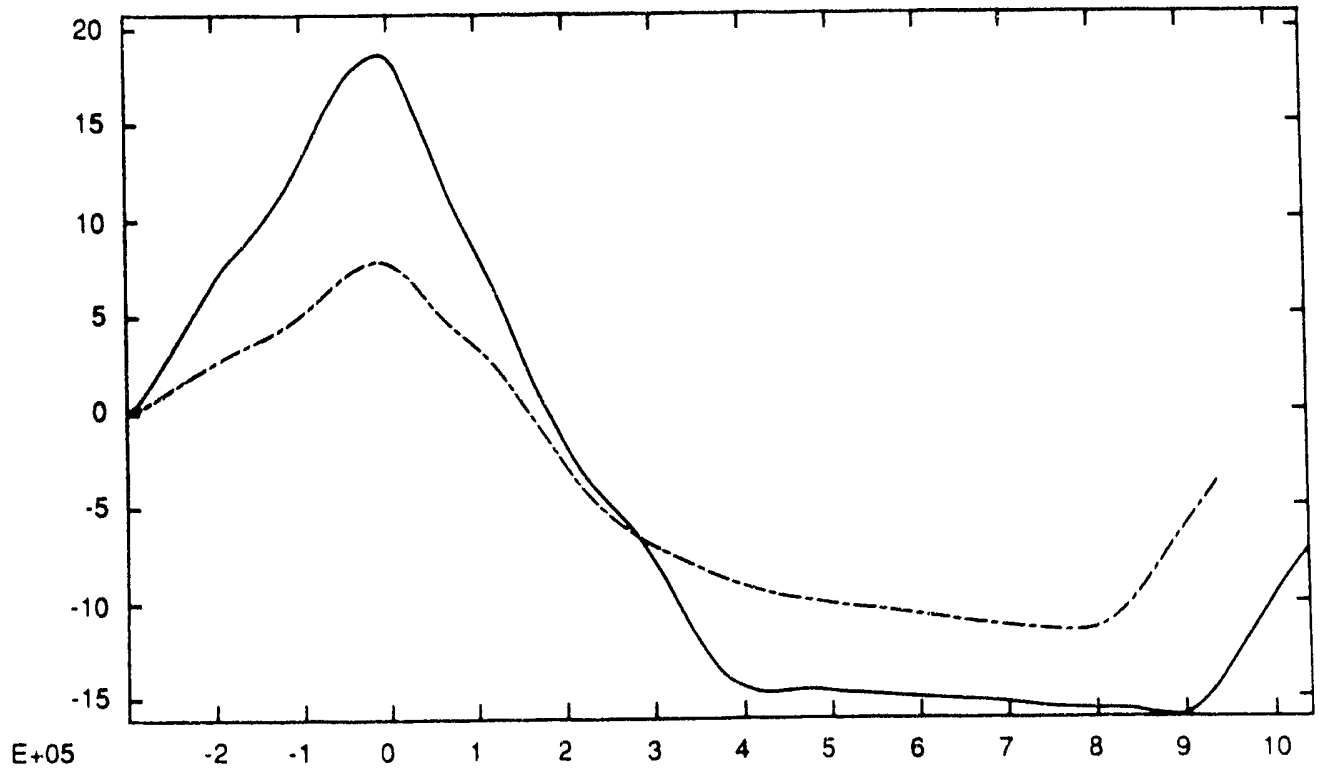

Figure 9 Current in PF coil \#4 as function of time.

Solid line - low resistivity case

Dotted line - high resistivity case 


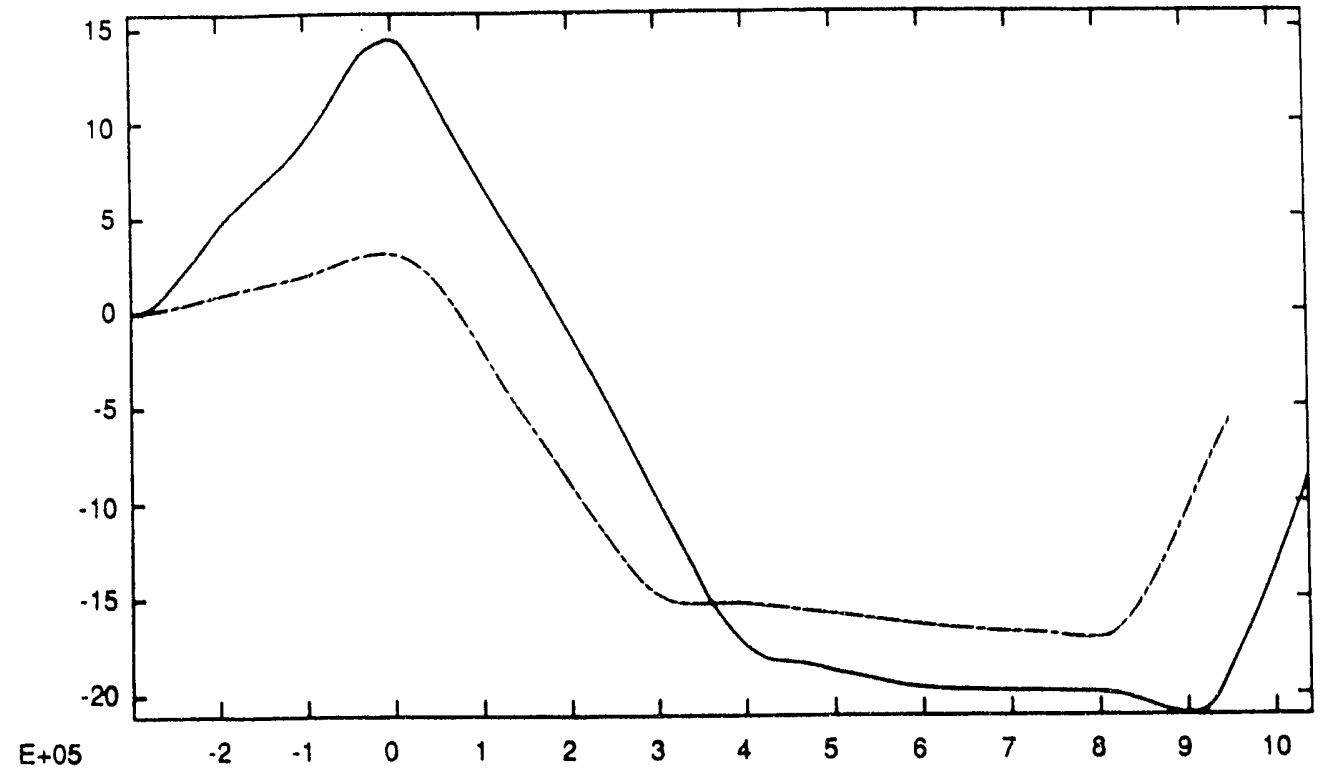

Figure 10 Current in PF coil \#5 as function of time:

Solid line - low resistivity case

Dotted line - high resistivity case 


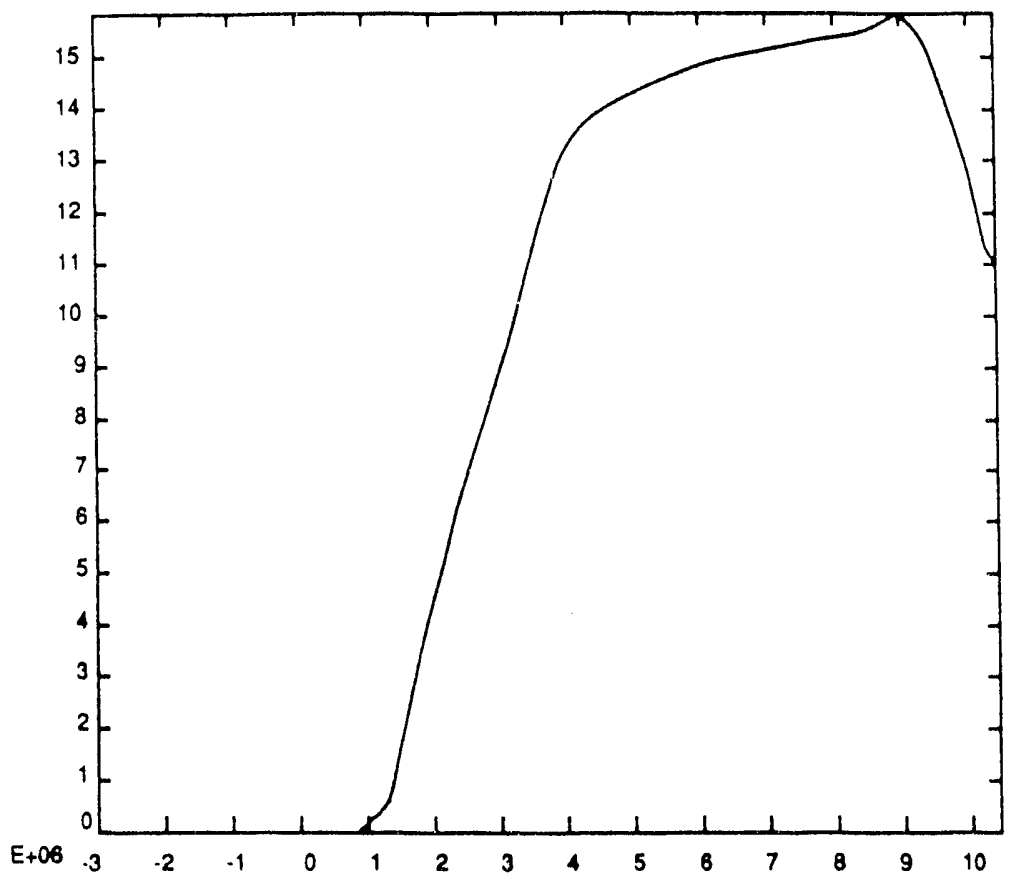

Figure 11 Induced plasma current as function of time in the low resistitivity case.

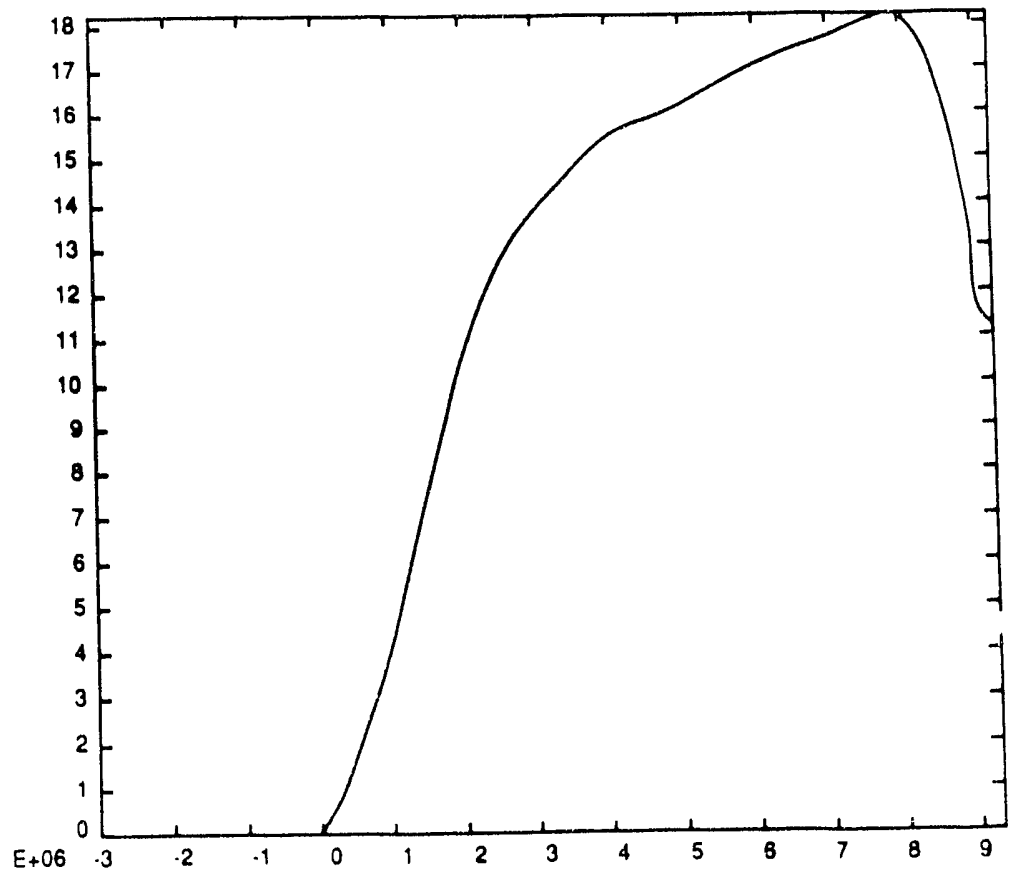

Figure 12 Induced plasma current as function of time in the high resistivity case. 


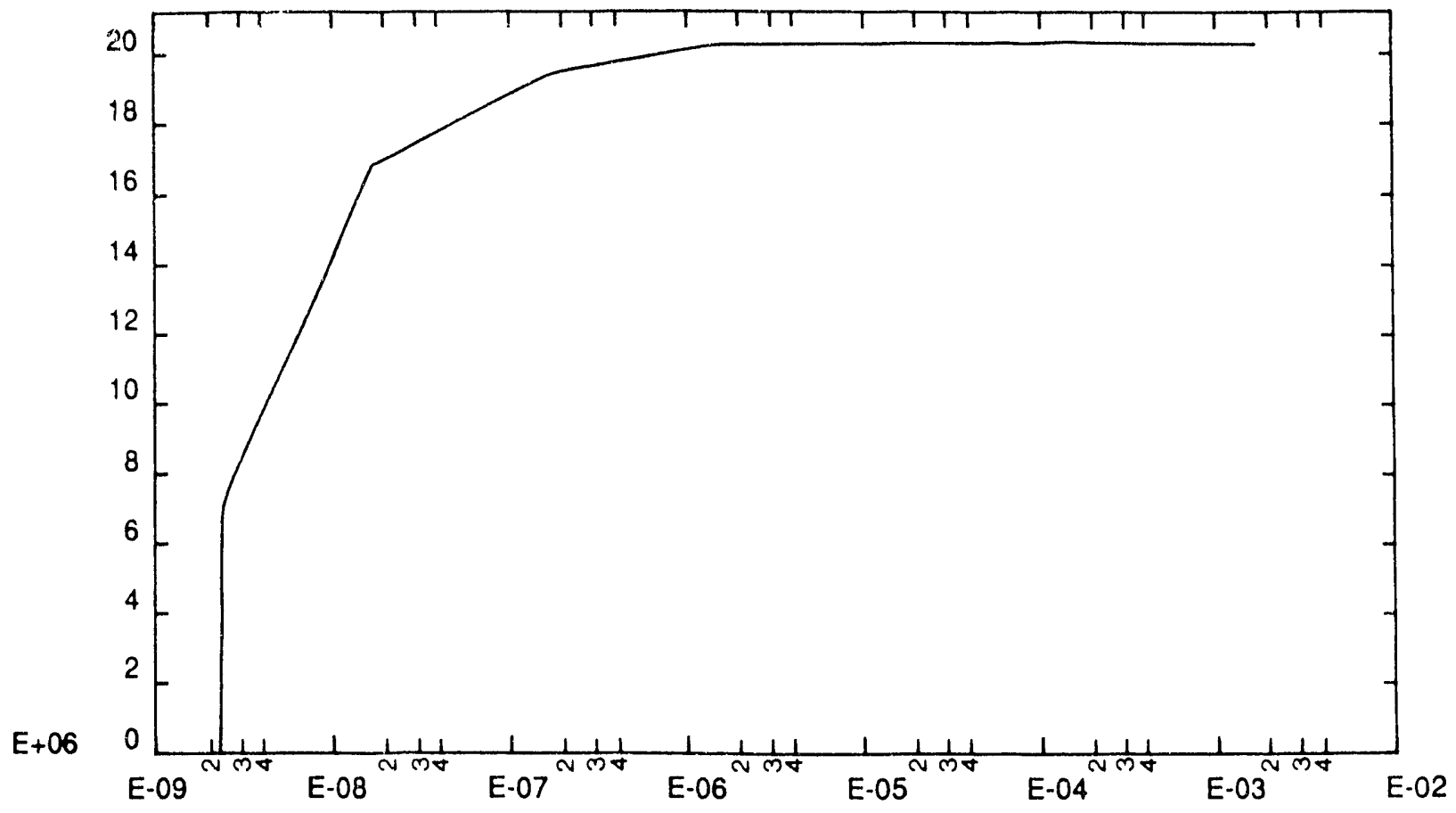

Figure 13 Induced plasma current as $\mathrm{t}=5$ seconds for different structure resistivity and same PF coil current waveforms.

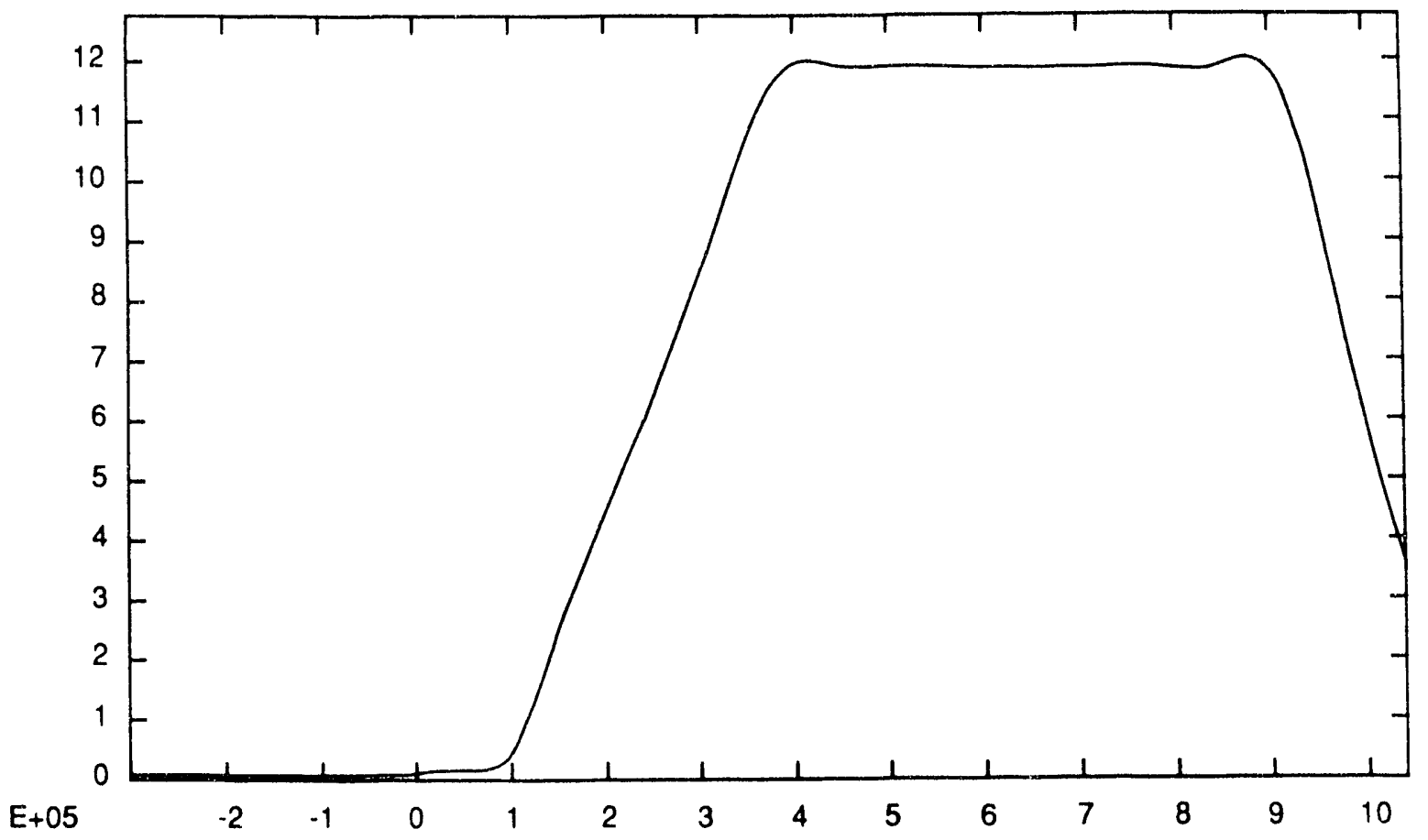

Figure 14 Plasma current as function of time for equilibrium calculation. 

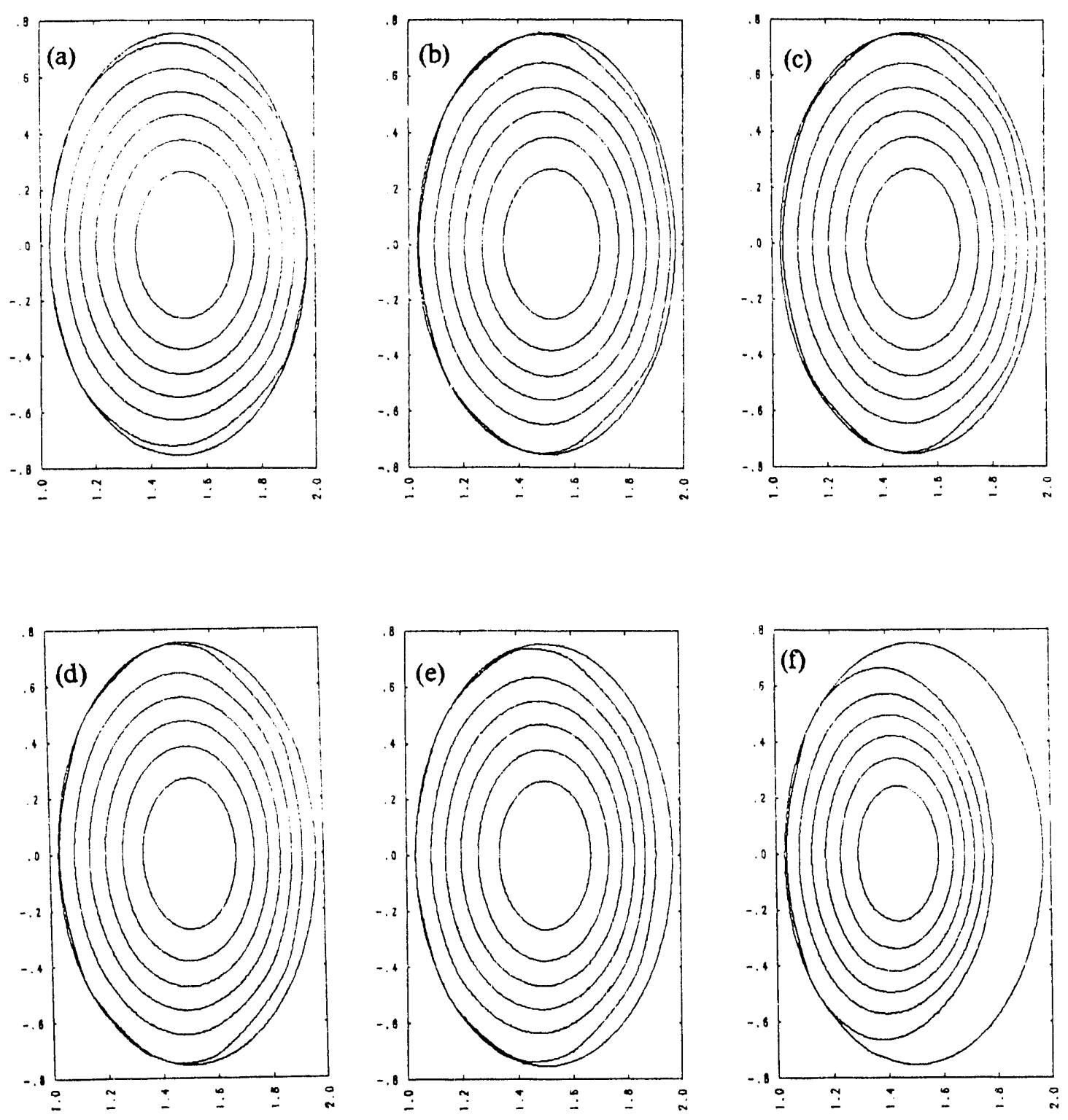

Figure 15 MHD equilibrium flux surfaces for IGNITEX discharge.

(a) $\mathrm{t}=3.0$, (b) $\mathrm{t}=4.0$, (c) $\mathrm{t}=5.0$, (d) $\mathrm{t}=7.0$, (e) $\mathrm{t}=9.0$, (f) $\mathrm{t}=10.4$ 

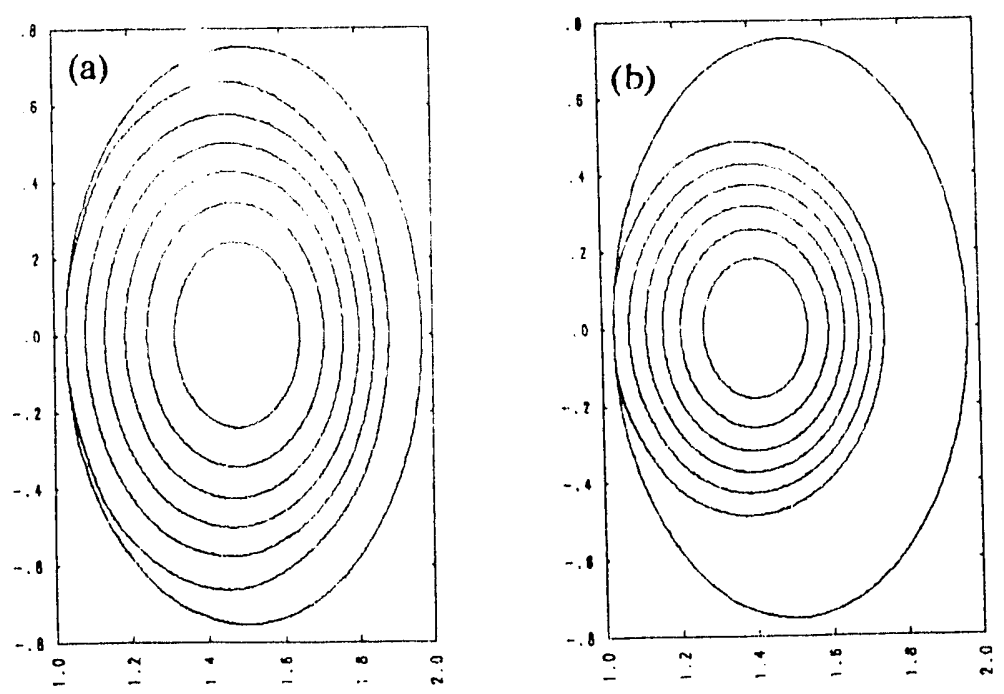

Figure 16 Magnetic flux surfaces at $t=5$ seconds

(a) without diffusive region effects; (b) without both diffusive region effects and virtual coil effects. 

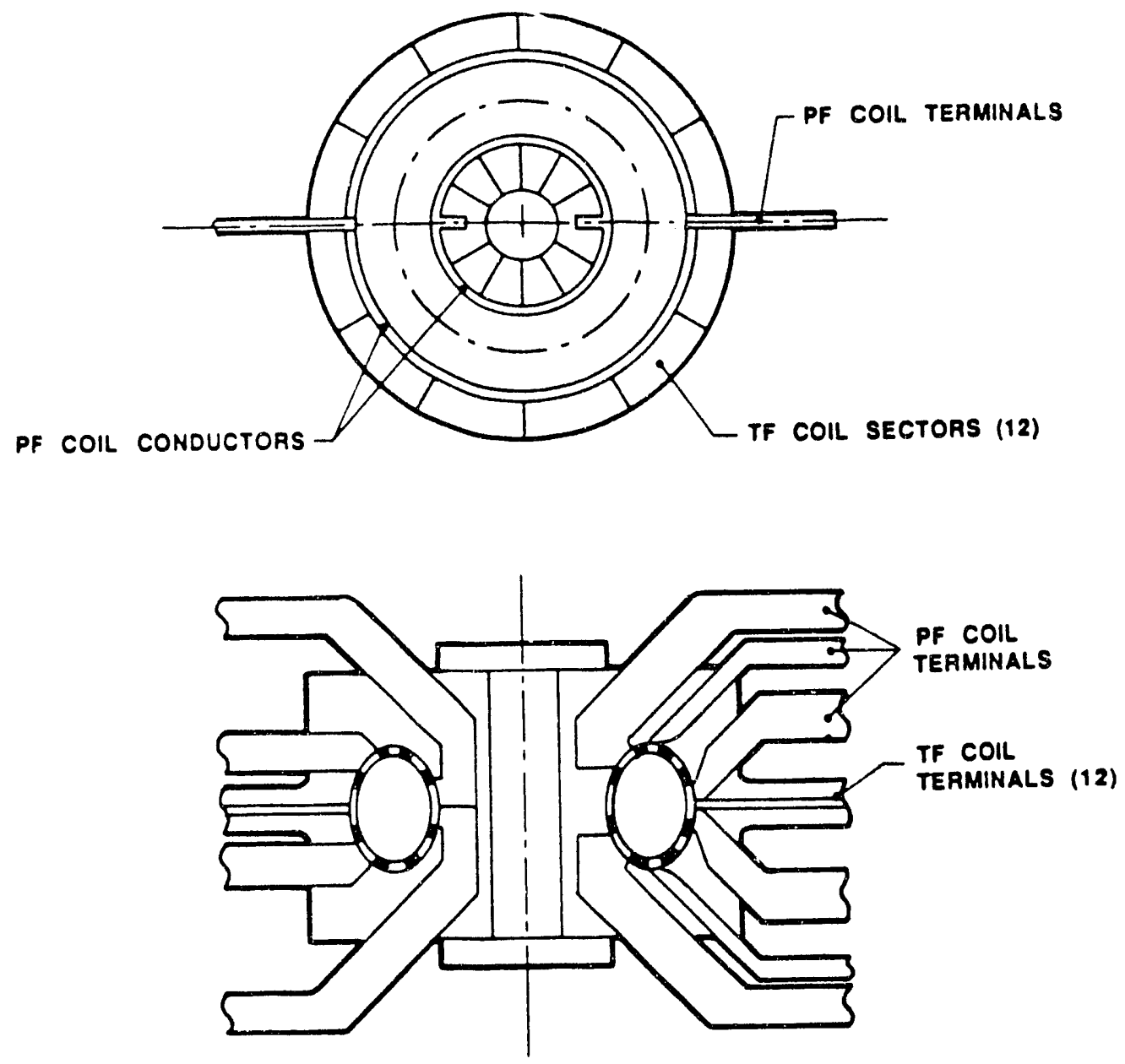

Figure 17 Arrangement of the poloidal field system leads in IGNITEX. 


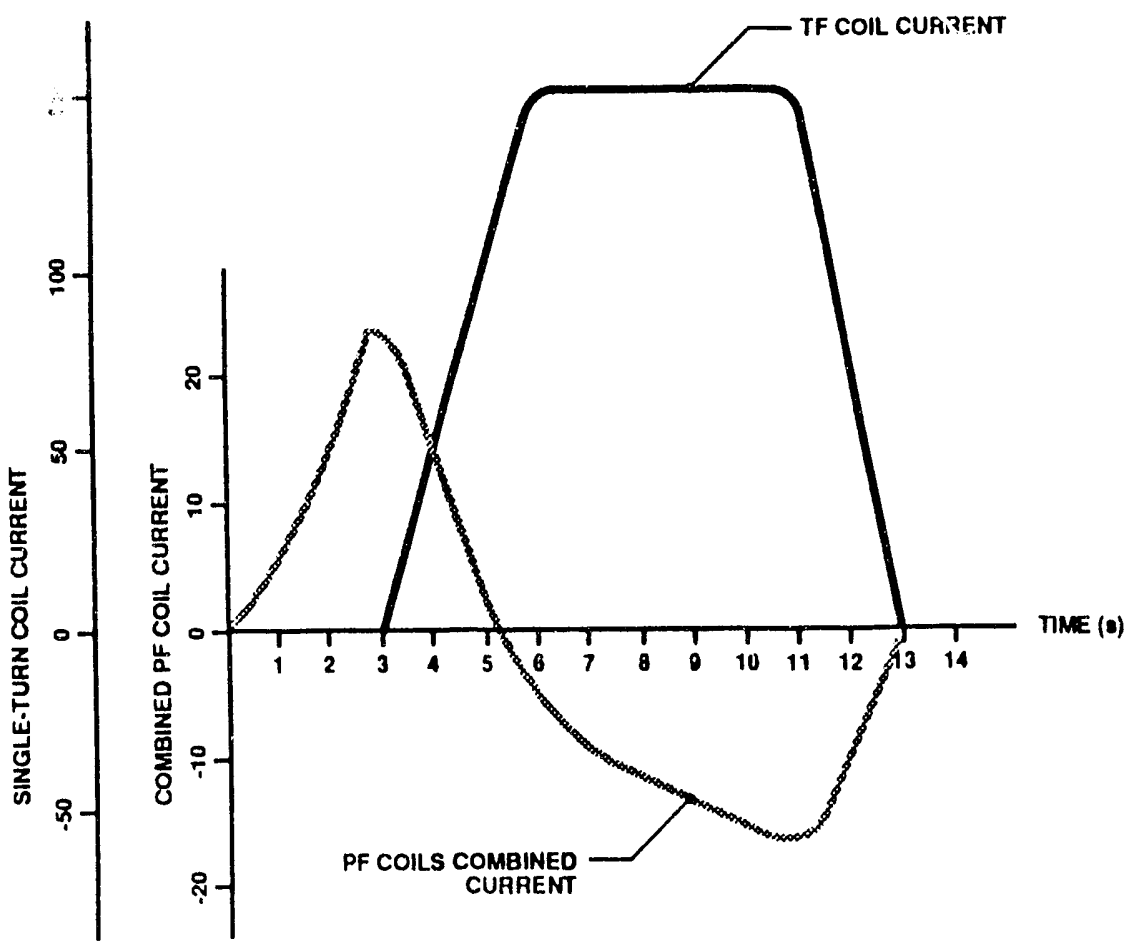

Figure 18 Pulse requirements for the IGNITEX magnet system. 


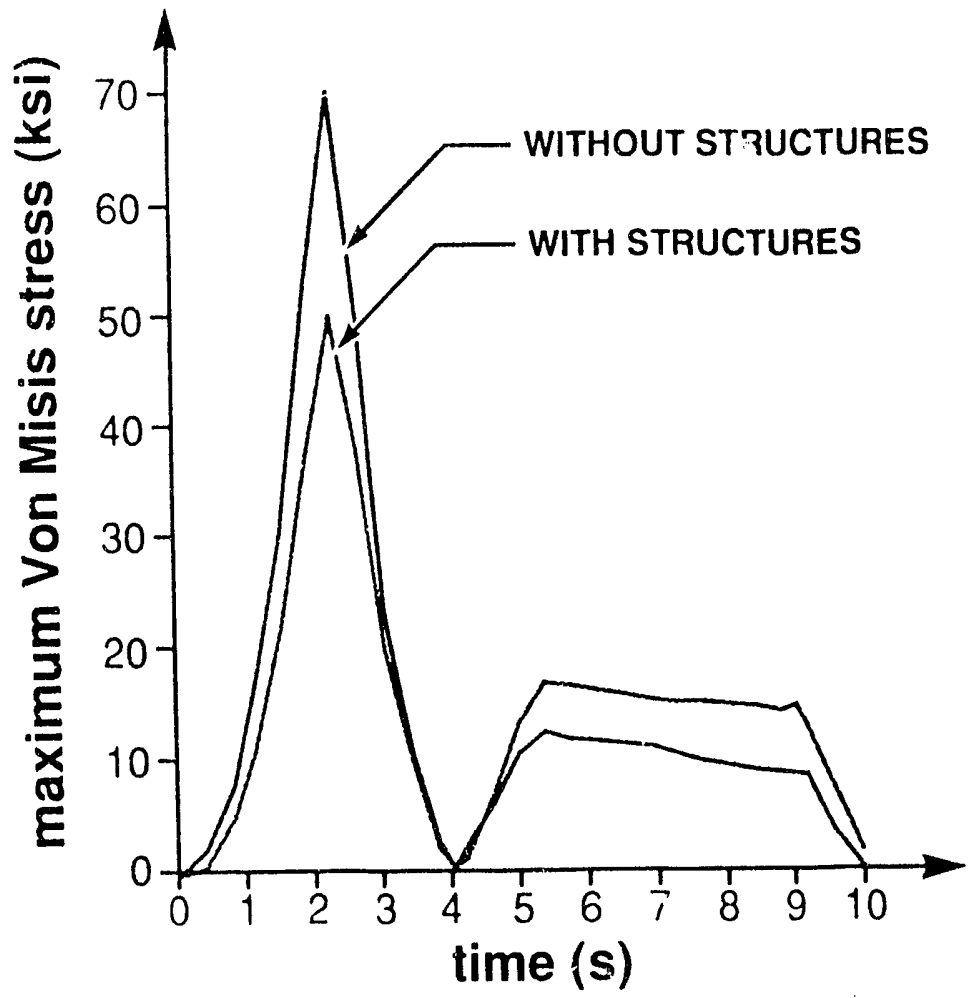

Figure 19 Time dependent variation of the von Mises stress in the unsupported PF coil \#1 of IGNITEX. 


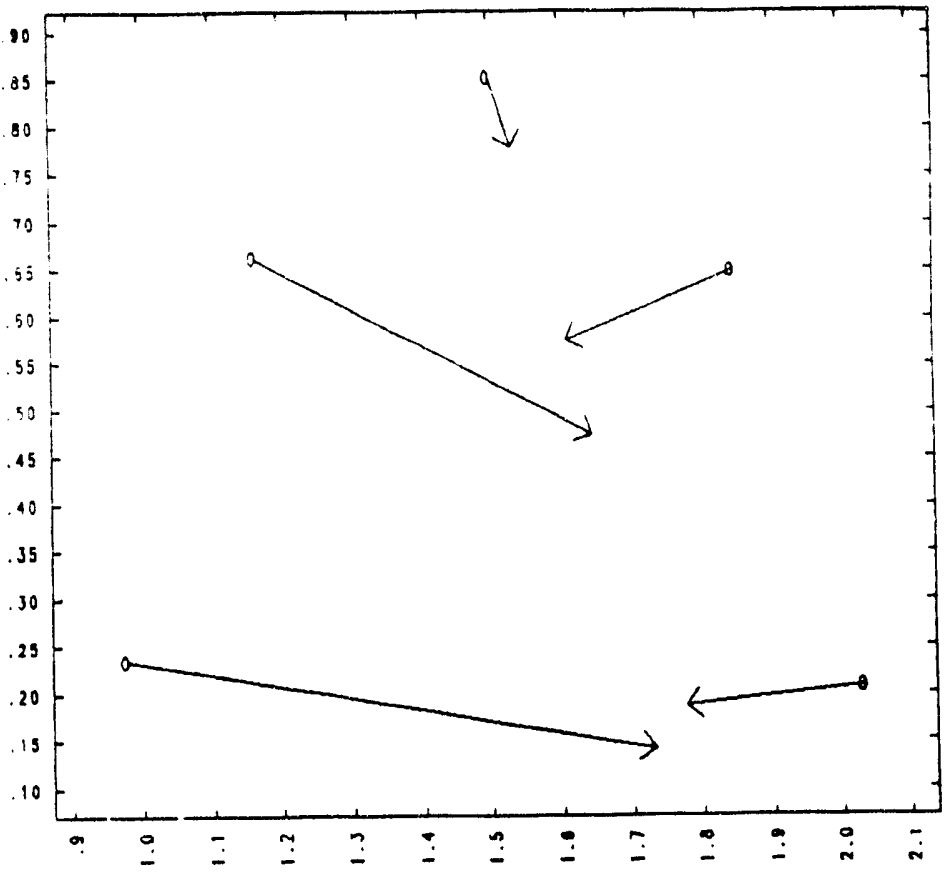

WITH STRUCTURES

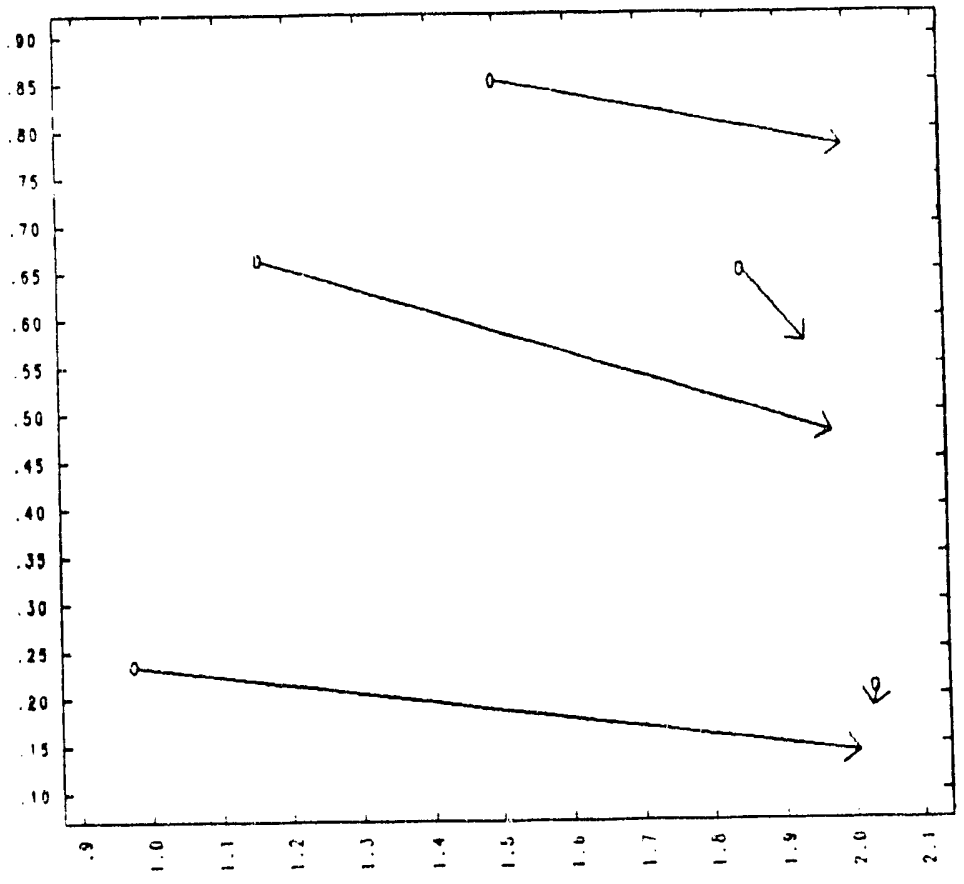

WITHOUT STRUCTURES

Figure 20 Von Mises stress on the five upper half-plane PF coils at time $=0$. The length of the arrows is proportional to stress and their direction corresponds to the direction for the force applied to each coil. Numerical values for PF coil \# 1 are given in Figure 19. 


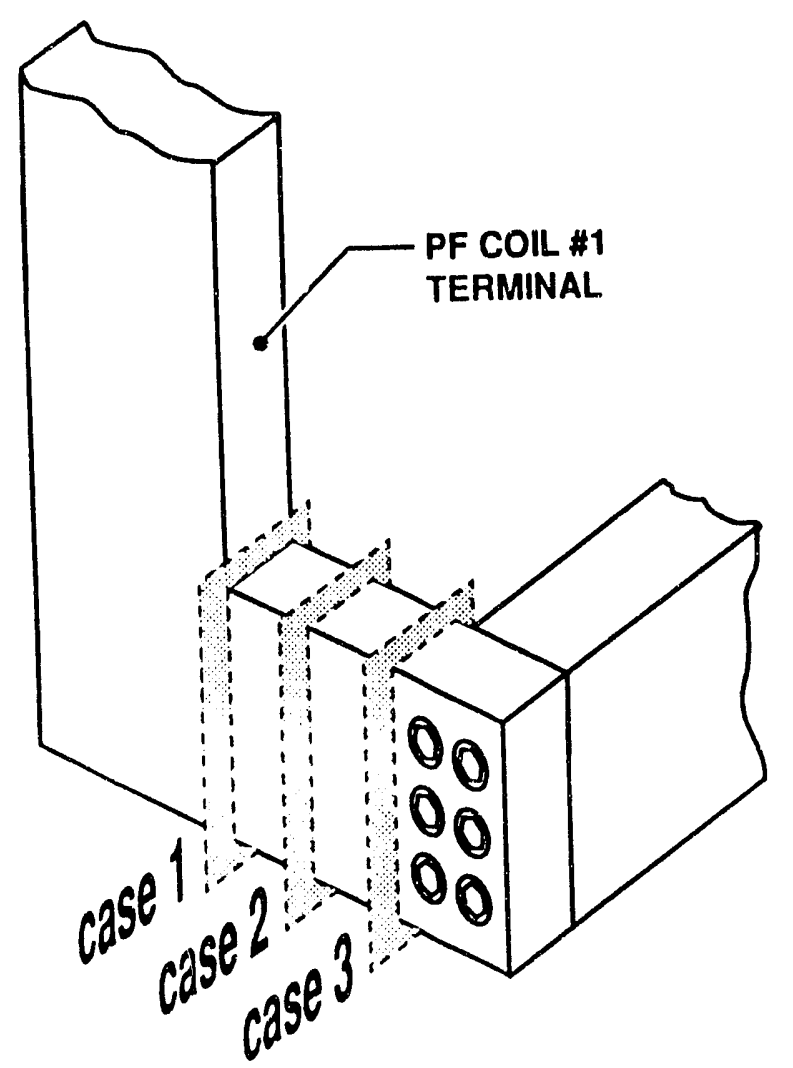

Figure $21 \quad$ Model lead used in the calculation of von Mises stress.
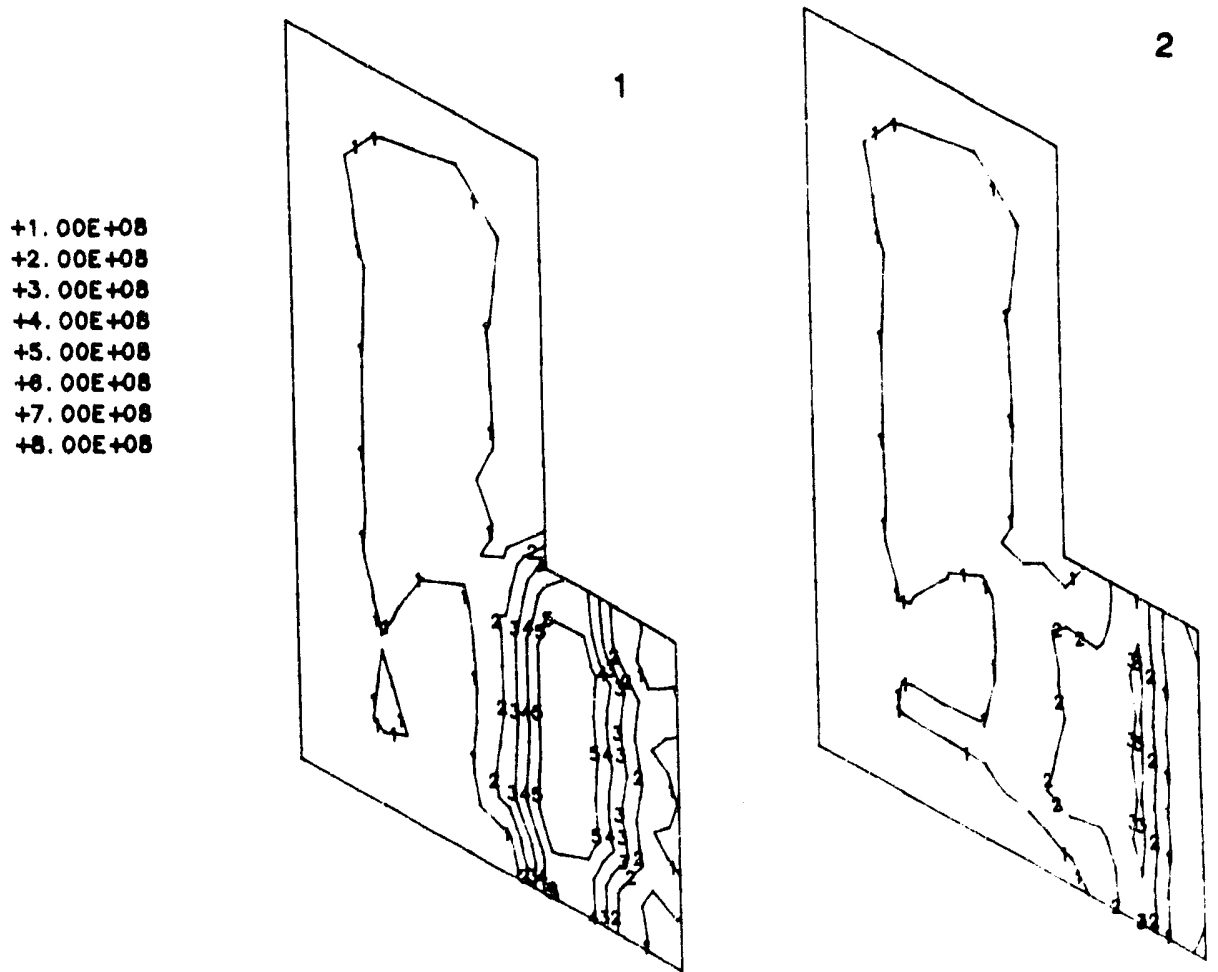

Figure 22 Von Mises contours (MKS units) for cases 1 and 2 (described in the text). 


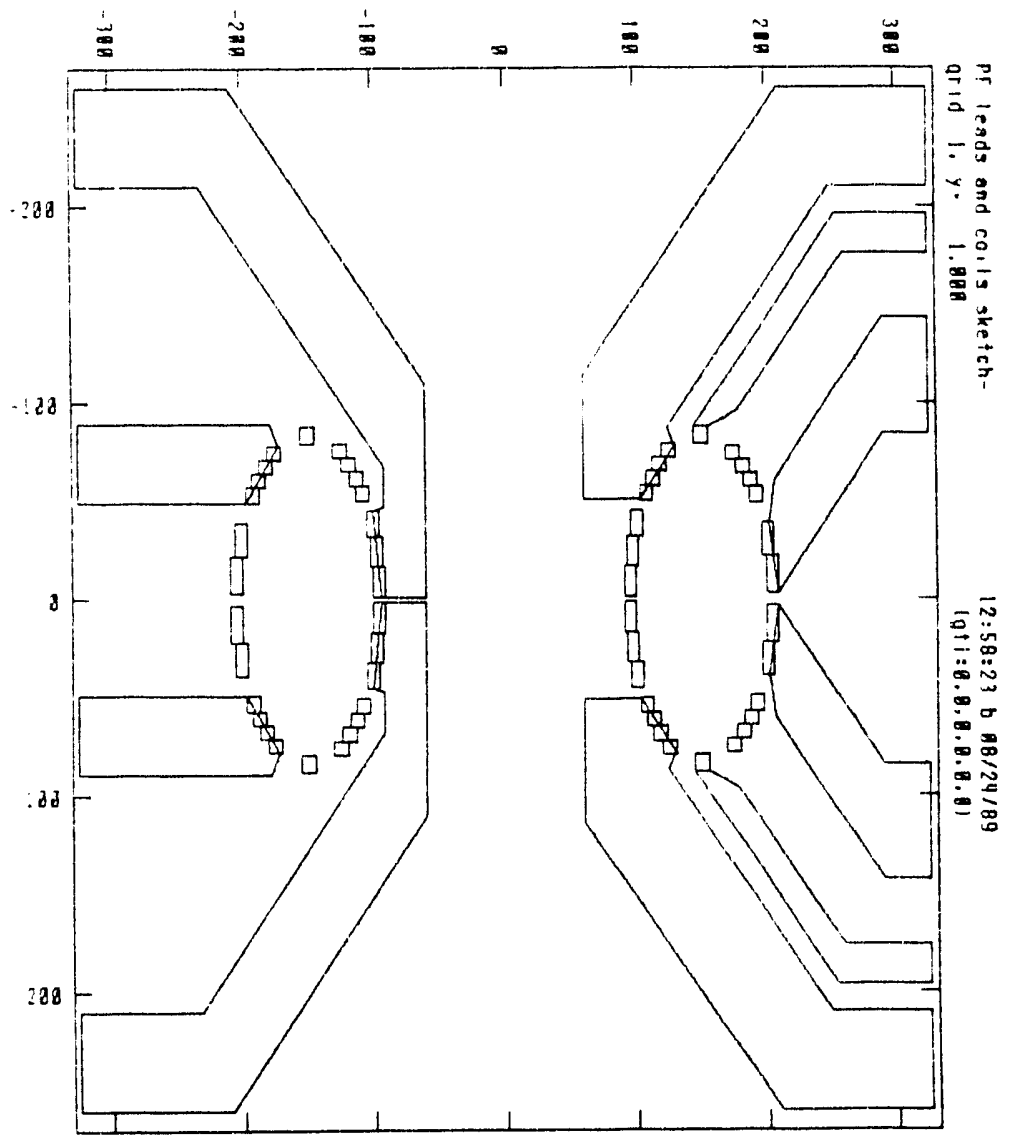

Figure 23 Model of the PF coils and PF leads used in the calculations of the perturbed magnetic field. 


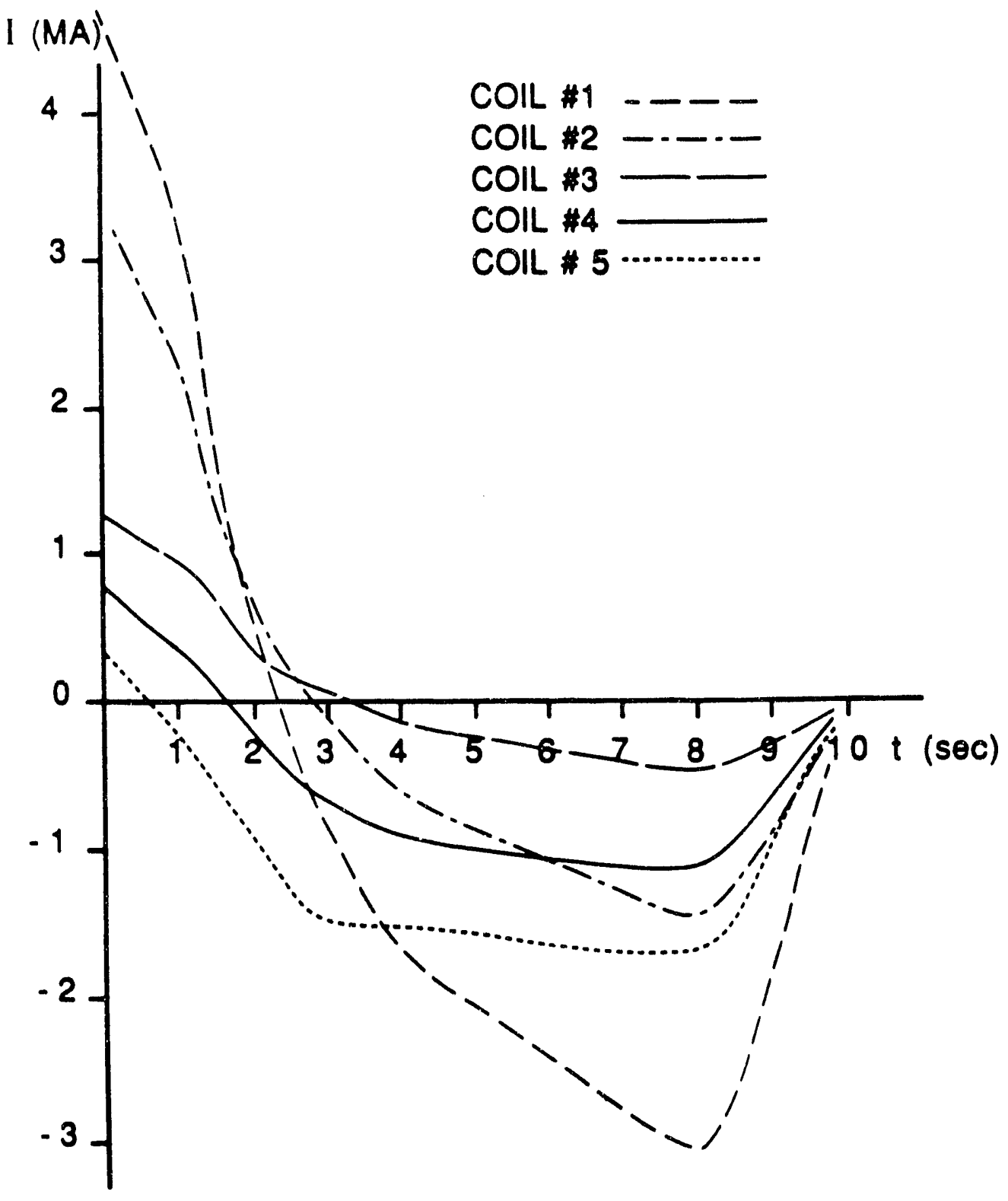

Figure 24 Coil currents in the poloidal field magnet system as a function of time (no structural effects are taken into account). 


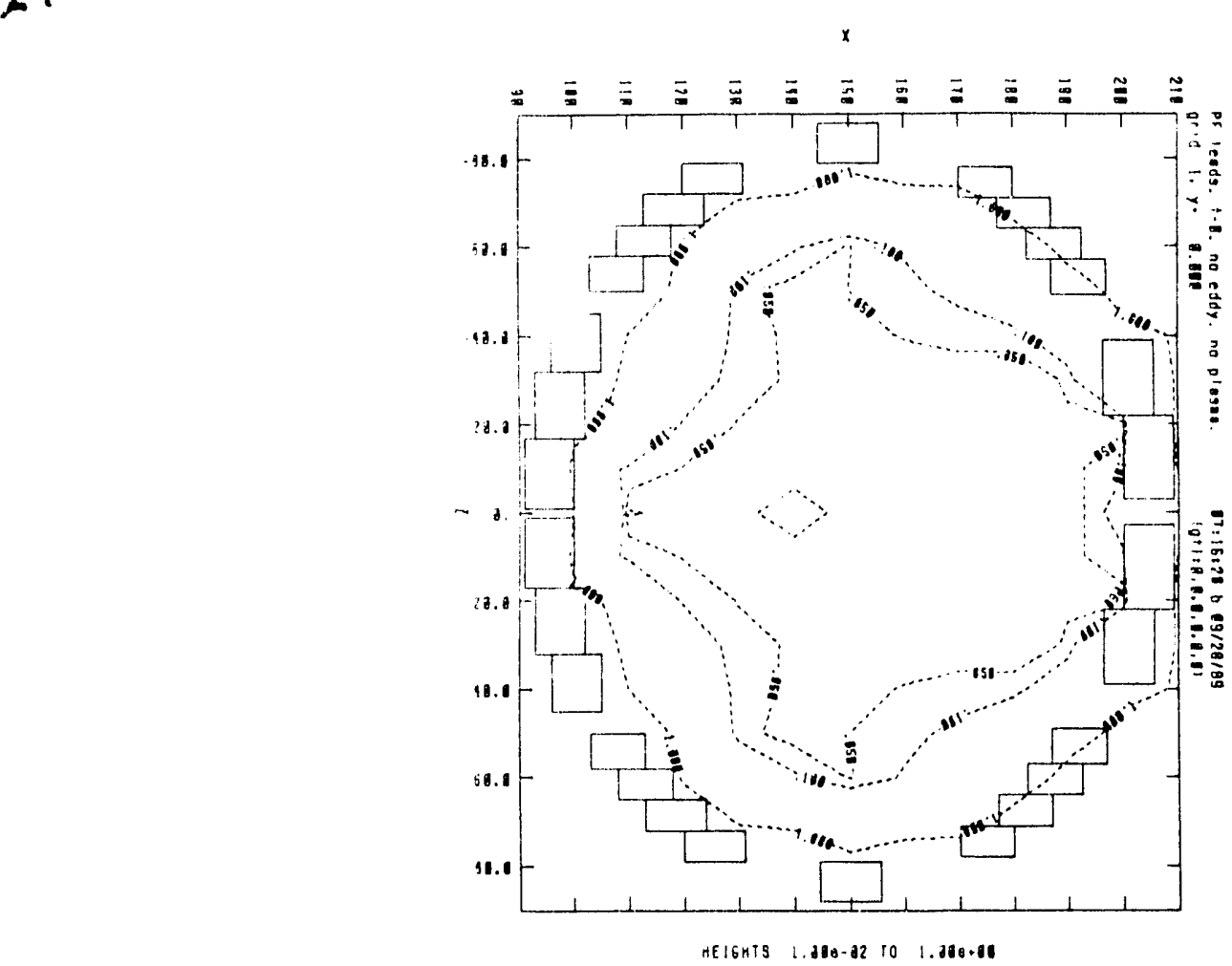

a)

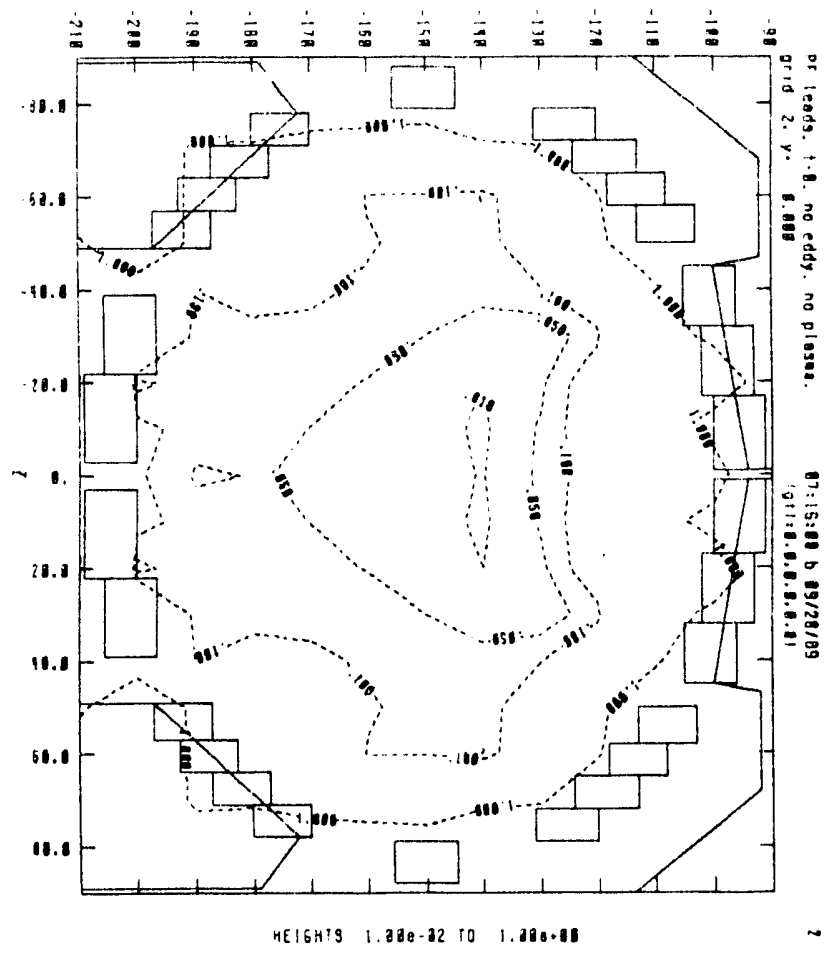

b)

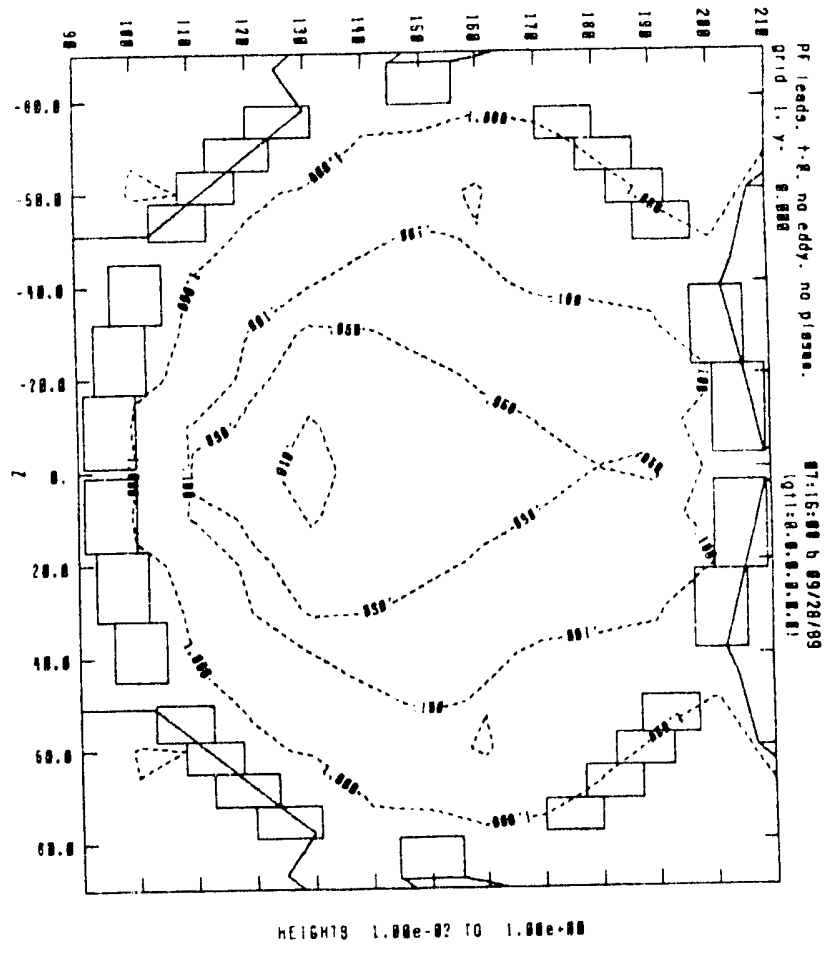

a)

Figure 25 Contours of the total magnetic field at plasma breakdown. produced by the PF coils and leads: a) unperturbed fieid; b) cross section at the location of leads \#2,3,5:c) cross section at the location of leads \#1 and 4 . 

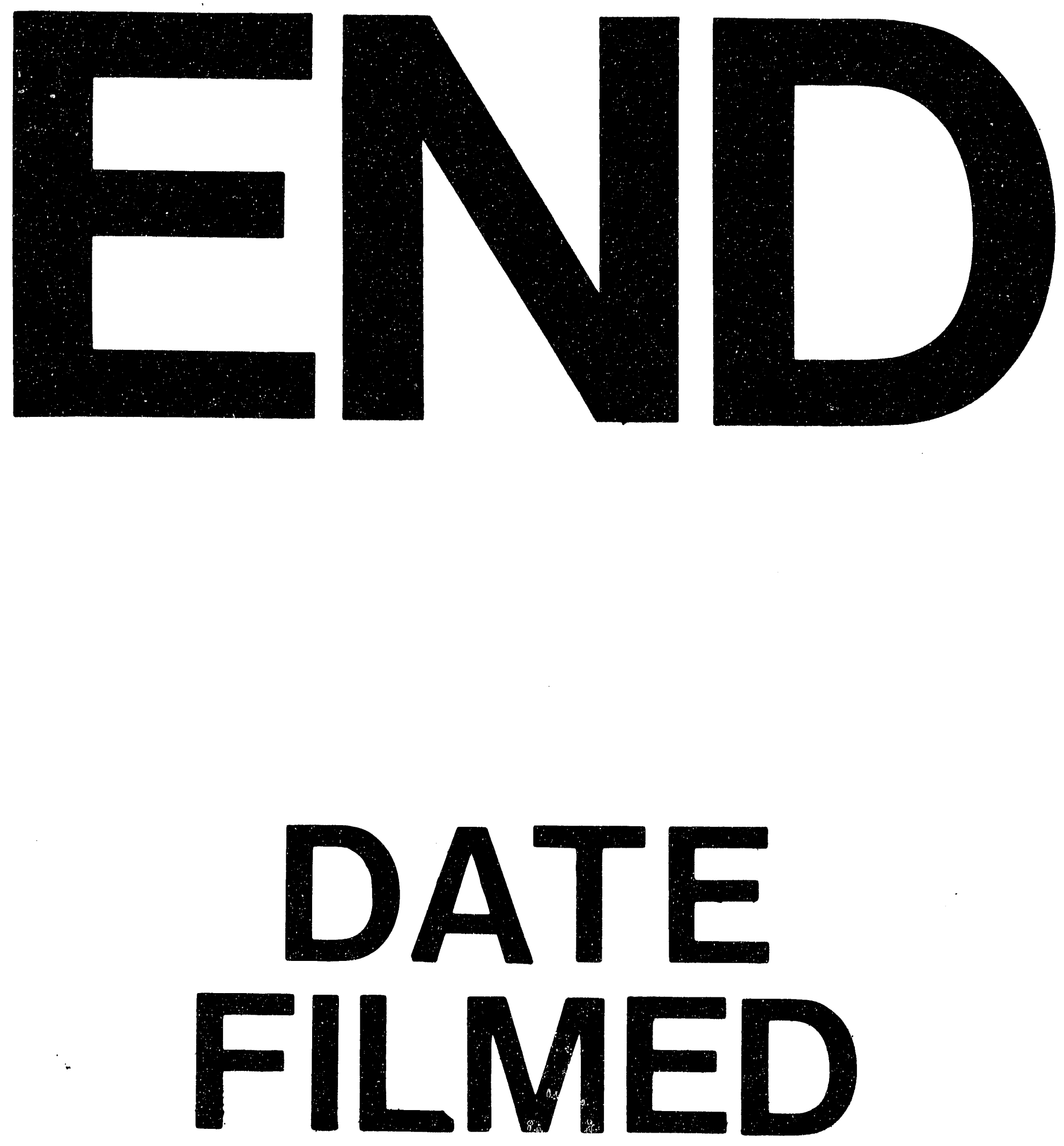

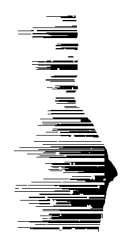

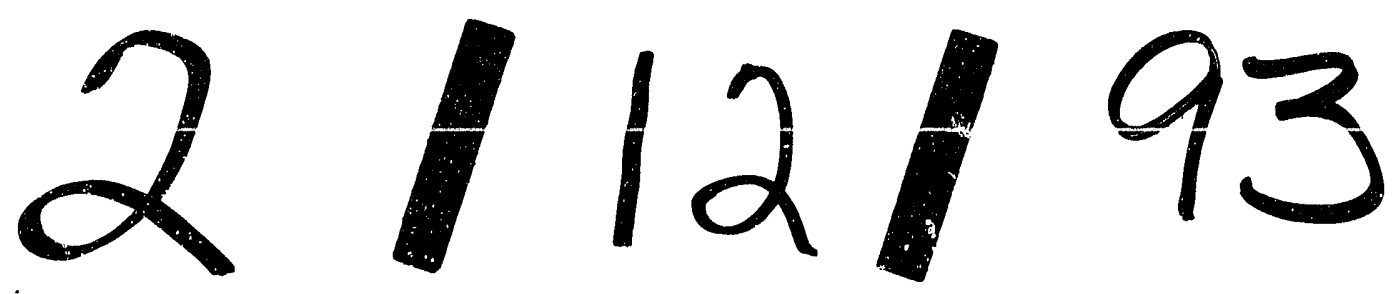


